\title{
Die Entstehung des modernen Hamburger Hafens (1866-1896)
}

\author{
Teuteberg, Hans Jürgen
}

First published in:

Tradition, 17. Jg., 5./6. Heft, S. 257 - 291, München 1972

Münstersches Informations- und Archivsystem multimedialer Inhalte (MIAMI)

URN: urn:nbn:de:hbz:6-30479542865 


\section{DIE ENTSTEHUNG DES MODERNEN HAMBURGER HAFENS (I866-I896)*}

Der Hamburger Hafen, wie er uns in seiner modernen Gestalt heute entgegentritt, und auch seine Arbeiterschaft sind ziemlich genau vor einhundert Jahren zu Beginn des Bismarck-Reiches entstanden. Dieses Jubiläumsdatum könnte allein als Legitimation dienen, sich rückschauend damit zu beschäftigen. Es gibt aber noch einen anderen Anlaß, sich dieser Problematik gerade jetzt wieder zuzuwenden.

Es besteht heute weitgehend Konsens darüber, daß die Erforschung der Industrialisierungsvorgänge in Deutschland besonders in den frühen Phasen zu einer der vordringlichsten Aufgaben der Geschichtswissenschaft herangewachsen ist ${ }^{1}$. In diesem Bezugsrahmen spielt die Industrialisierung der norddeutschen Küstenstädte eine große Rolle, weil sich hier spezifische und sonst nirgendwo in dieser Form anzutreffende Strukturwandlungen vollzogen haben. Was nun Hamburg betrifft, so stellt der Übergang vom jahthundertealten, relativ primitiven Naturhafen zum modernen, hochmechanisierten und rationalisierten Kunsthafen mit allen damit zusammenhängenden technischen Innovationen und wirtschaftlich-sozialen Begleiterscheinungen den entscheidenden Schritt ins industrielle Zeitalter dar. Es kann keinen Zweifel darüber geben, daß der Ausbau des Hamburger Hafens seit 1866 die Stadt bis in die letzten Grundstrukturen hinein verwandelt hat. Die Bedeutung dieses Vorganges liegt nicht nur darin, daß z.B. die Umschlagkosten bis zu 60 v.H. vermindert wurden, sondern $\mathrm{da}$ der Hafenausbau zugleich auch mit dem Beginn der hochkapitalistischen Phase in der Hansestadt zusammenfällt. Vom Standpunkt des Wirtschafts- und Sozialhistorikers ist das eine ganz entscheidende Zäsur, denn hier wird das vorindustrielle, noch viele mittelalterliche Züge tragende, behäbige »Merry old Hamburg" von der industriell orientierten modernen Großstadt von heute geschieden. Die vereinzelt in den Hamburgiensien anzutreffende Ansicht, die Hamburger Industrialisierung sei mit dem Aufbau der ersten industriellen Großbetriebe allein identisch, ist völlig abwegig und eine Verkennung des komplexen Industrialisierungsbegriffes.

Darüber hinaus kann die Modernisierung des Hamburger Hafens aber auch als ein Kernstück unserer gesamten "Industriellen Revolution" in Deutschland gedeutet werden. Blättert man die maßgebenden historischen Hand- und Lehrbücher durch, so

\footnotetext{
* Dieses Thema bildete zum Teil den Gegenstand eines Vortrages, den der Verf. am 4. März I970 vor dem "Verein für Hamburgische Geschichte» gehalten hat. Für den vorliegenden Zweck wurde die Abhandlung wesentlich überarbeitet. Fräulein Ursula Peters und Herrn Franz Lorenz habe ich für Unterstützung zu danken. 1 Otto Biisch, Industrialisierung und Geschichtswissenschaft, Berlin 1969. - Wolfram Fischer (Hrsg.), Wirtschaftsund sozialgeschichtliche Probleme der frühen Industrialisierung, Berlin I968, S. I-20 (Einleitung).
} 
wird man freilich nur wenig über die Bedeutung des Hamburger Hafenausbaus und seine Einwirkung auf die Wandlungen der deutschen Volkswirtschaft im großen finden. Überhaupt scheint der Mangel einer über die lokalen Grenzen hinausreichenden Hamburger Wirtschaftsgeschichte, den der frühere Direktor der Commerz-Bibliothek Eduard Rosenbaum und der Ökonom Erwin Wiskemann vor mehr als einer Generation lebhaft beklagten, immer noch nicht befriedigend behoben zu sein ${ }^{2}$. Die nachfolgenden Ausführungen sollen zunächst daher den Blick darauf lenken, daß es höchste Zeit wird, die bisher im heimatgeschichtlichen Rahmen gewonnenen Erkenntnisse über die Hafenmodernisierung aufzuarbeiten und in die großen repräsentativen Gesamtdarstellungen einfließen zu lassen. Die Geschichte des Hamburger Hafens kann weit mehr als ein lokales Interesse beanspruchen - es ist ein erregendes Thema von gesamthistorischer Relevanz. Die zur Zeit mit Vorrang betriebene Geschichte der deutschen Frühindustrialisierung zeigt, daß man ohne die wertvollen Resultate der Landes- und Lokalgeschichte überhaupt nicht weiterkommt. Immer mehr erweist sich, daß viele der deduktiv gewonnenen Theorien über die Ursachen beschleunigten wirtschaftlichen Wachstums in der Vergangenheit, die wir mit der Chiffre Industrialisierung zu bezeichnen uns gewöhnt haben, noch dringend der Überprüfung am historischen Einzelobjekt bedürfen. Die Geschichte der Industrialisierung im Deutschland des I9. Jhs. ist, da es zunächst noch keinen Einheitsstaat und keine einheitliche Volkswirtschaft gegeben hat, vor allem Landes- oder sogar wie in diesem Fall Stadtgeschichte ${ }^{3}$. Wenn wir uns so sehr für die Genesis des modernen Hamburger Hafens interessieren, so geschieht dies also auch aus übergeordneten Erwägungen.

Wie sieht nun der Stand unserer Erkenntnis auf dem Gebiet der Hamburger Hafengeschichte aus? Wirft man einen Blick in die Bibliographien, so muß man von der Quantität einschlägiger wirtschaftsgeschichtlicher Literatur beeindruckt sein ${ }^{4}$. Ohne Zweifel hat Hamburg, nicht zuletzt durch die stete Förderung des mehr als einhundert Jahre alten "Vereins für Hamburgische Geschichte», auf diesem Sektor mehr aufzuweisen als vergleichbare andere Städte. Von Johann Georg Büsch, der Ende des I 8. Jahrhunderts Wesen und Bedingungen der Hamburger Wirtschaft zum Nutz und Frommen seiner Kaufmannschaft erstmals untersuchte, über Adolph Soetbeer, Karl Koppmann, Richard Ebrenberg, Adolph Woblwill, Ernst Baasch, Hans Nirrnbeim und Otto Riidiger bis zu Heinrich Reincke, Gustav und Jïrgen Bolland, Percy Ernst Schramm, Ernst Hieke, Dietricb Kausche und Güntber Jantzen reichen die bekanntesten Namen Hamburger Historiker, die das Wirtschafts- und Verfassungsleben der Stadt in früheren Zeiten aufgehellt haben. Sieht man sich diese Arbeiten näher an, so ist ein überwiegendes Interesse an der Geschichte des Handels und verwandter Sachgebiete unverkennbar.

2 Eduard Rosenbaum in einer Rezension im Weltwirtschaftlichen Archiv Jg. I916. - Erwin Wiskemann, Hamburg und die Welthandelspolitik von den Anfängen bis zur Gegenwart, Hamburg 1929 (Einleitung).

${ }^{3}$ Vergl. die gedanklich sehr anregende Abhandlung von Erich Mascbke, Industrialisierungsgeschichte und Landesgeschichte, in: Blätter für deutsche Landesgeschichte Jg. I03 (I967), S. 7 I-84.

4 Herangezogen wurden Kurt Detlev Möller zind Ameliese Tecke, Bücherkunde zur Hamburgischen Geschichte, 2 Bde., Hamburg 1939-1956, und Erich von Lebe u.a., Heimatchronik der Freien und Hansestadt Hamburg, 2. erw. und verb. Aufl., Köln I967, S. 597-618. 
Die Geschichte der „Commerzdeputation«, der Handelsverträge, Handelskonsulate, Handelsbücher und Handelsstatistik, der Handelsschiffahrt sowie einzelner Handelshäuser und Handelsfamilien ist bereits erfreulich intensiv durchforscht. Einzelne Historiker sind verständlichen eigenen genealogischen Interessen nachgegangen und haben bei dieser Gelegenheit weit über die Familiengeschichte hinausgehende Beiträge zur typologischen Entwicklung des deutschen Bürgertums vorgelegt, wobei vor allem an die klassisch gewordenen Familienmonographien von Richard Hertz, Heinrich Sieveking und Percy-Ernst Scbramm zu erinnern ist ${ }^{5}$. Diese Forscher haben gezeigt, daß hanseatische Kaufleute zu den farbigsten Figuren deutscher Wirtschaftsgeschichte gehören und bestimmte Abschnitte darin ohne ihr Wirken schlechterdings nicht vorstellbar sind.

Aber alle diese faszinierenden Einzelstudien spiegeln bekanntlich noch keineswegs die gesamte Hamburger Entwicklung wider. Bei vielen Sachverhalten tappen wir noch völlig im Dunkeln, vor allem bei bestimmten Querverbindungen von Staat, Wirtschaft und Gesellschaft. Die Fülle der topographischen, familiären, technischen, wirtschaftsund verwaltungsgeschichtlichen Studien darf uns nicht darüber hinwegtäuschen, daß es an einer wirklich zulänglichen großen Darstellung über die Entwicklung des hochkomplexen Organismus der modernen Hafen-, Industrie- und Großhandelsstadt Hamburg noch fehlt. Die bloße Addition von Börsen-, Verkehrs-, Industrieeinrichtungen, von Hafenbecken, Pferdestärken, Maschinen und Arbeiterzahlen, wie sie hier und da vorgenommen wurde, ergibt in summa noch nichts. So vorzüglich die ältere Wirtschaftsgeschichte Hamburgs bereits bearbeitet ist, so lückenhaft und unbefriedigend erscheint sie für die jüngste Zeit vom I9. Jahrhundert bis zur Gegenwart. Alle repräsentativen Gesamtdarstellungen offenbaren, daß Hamburgs Industrialisierungsgeschichte erst noch geschrieben werden muß. Vieles bedarf zudem aus der älteren Forschung einer kritischen Durchmusterung und Ergänzung durch die an anderen Orten inzwischen gewonnenen Einsichten. Die Arbeiten von Erwin Wiskemann über Hamburg und die Welthandelspolitik aus dem Jahre 1929 und Helmut Böbmes neuerdings vorgelegter Versuch, politisch-verfassungsrechtliche und sozio-ökonomische Probleme der neueren Hamburger Geschichte zusammenzusehen, können in diesem Sinne als methodisch anregende Arbeiten hierfür bezeichnet werden ${ }^{6}$.

Wie sieht nun die vorliegende Literatur zur Geschichte des Hamburger Hafens in großen Zügen aus? In der ersten Ausbauphase bis kurz nach dem I. Weltkrieg sind

- Richard Hertz, Das Hamburger Seehandlungshaus J. C. Godeffroy \& Sohn 1766-1789, 2. Aufl., Hamburg 1962. - Heinricb Sieveking, Georg Heinrich Sieveking. Lebensbild eines hamburgischen Kaufmannes aus dem Zeitalter der Französischen Revolution, Berlin I913. - Ders., Karl Sieveking. Lebensbild eines hamburgischen Diplomaten aus dem Zeitalter der Romantik, 3 Bde., Hamburg 1923-1928. - Percy Ernst Scbramm, Kaufleute zu Haus und Übersee. Hamburgische Zeugnisse des I7., I8. und I9. Jahrhunderts, Hamburg 1949. - Ders., Deutschland und Übersee. Der deutsche Handel mit den anderen Kontinenten, insbesondere mit Afrika, von Karl V. bis zu Bismarck, Braunschweig und Hamburg I950. - Ders., Hamburg, Deutschland und die Welt. Leistung und Grenzen hanseatischen Bürgertums in der Zeit zwischen Napoleon I. und Bismarck, München 1948. - Ders., Neun Generationen, 2 Bde., Göttingen $1_{9} 6_{3} / 6_{4}$.

- Wiskemann, a. a. O. - Helmut Böbme, Hamburg und Frankfurt. Des Deutschen Reiches Silber- und Goldloch und die allerenglischste Stadt des Kontinents, Frankfurt/M. 1968. - Wiskemam, der aus Mühlhausen im ElsaB 
eine ganze Reihe Monographien entstanden, die in der Hauptsache von Ingenieuren, Verkehrsfachleuten, Geographen und Wirtschaftlern verfaßt wurden 7 . Einige von ihnen, wie der Hamburger Wasserbaudirektor Prof. Bubendey und seine Mitarbeiter bzw. Nachfolger Lorenqen, Meyer, Nebls, Böttcher und Wendemuth, wollten vor allem als Techniker von ihren Leistungen Zeugnis ablegen. Auch die Beschreibungen in dem Sammelwerk »Hamburg und seine Bauten« des Hamburger Architekten- und Ingenieurvereins von

stammte, war nach dem I. Weltkrieg wissenschaftlicher Assistent am Staatswissenschaftlichen Seminar der Universität Hamburg und nebenbei Leiter der Presseabteilung der Handelskammer. In dieser Zeit sammelte er die Materialien für sein wichtiges Buch, das er dann als Privatdozent für Volkswirtschaftslehre und Finanzwissenschaft schrieb. Offenbar ist Wiskemann durch seine Lehrer Rudolf Häpke und Walther Troeltsch sowie den damaligen Direktor der Hamburger Commerz-Bibliothek Eduard Rosenbaum (heute London) auf diese fruchtbare Fragestellung hingewiesen worden. Es erscheint angebracht, diese Forderung nach einer umfassenden und überlokal konzipierten Hamburger Wirtschaftsgeschichte wieder aufzugreifen.

? Ricbard Ebrenberg, Die Anfänge des Hamburger Freihafens, in: Ders., Wie Hamburg groß wurde, HamburgLeipzig I888. - Emanuel Fitger, Die Seehäfen Englands und ihre Ausrüstung mit Rücksicht auf die Hafenbauten beim Zollanschluß Hamburgs und Bremens, Berlin i 885. - Cbr. Nebls und J. F. Bubendey, Die Elbe, Hamburgs Lebensader, Hamburg 1892. - Carl Griese und Oskar Sclswindrazbeim, Der Hamburger Hafen, Hamburg I 896/97. M. Bucbheister, Die Elbe und der Hafen von Hamburg, in: Mittheilungen der Geographischen Gesellschaft Hamburg Bd. Is (1899). - Emantel Fitger, Die wirtschaftliche und technische Entwicklung der Seeschiffahrt, Leipzig I 902. - Kurt Wiedenfeld, Die nordwesteuropäischen Welthäfen London-Liverpool-Hamburg-Bremen-Amsterdam-Rotterdam-Antwerpen, in: Veröffentlichungen des Instituts für Meereskunde und des Geographischen Instituts an der Universität Berlin H. 3, Berlin I903, besonders S. r roff. - J. F. Bubendey, Der Hamburger Hafen, Hamburg rgrr. - J. F. Bubendey zind C. Lorenzen, Der Hamburger Hafen und die Regulierung der Unterelbe, in: Illustriertes Export-Handbuch der Börsenhalle r91 2-1914, Hamburg 191 2. - J. C. Bubendey und E. G. Meyer, Mechanische Hafenausrüstung, in: XII. Internationaler Schiffahrtskongreß, hrsg. vom internationalen ständigen Verband der Schiffahrtskongresse, Philadelphia r91 2. - M. F. Arndt, Seehafenentwicklung unter besonderer Berücksichtigung des Hamburger Hafens, Berlin I913. - Richard Linde, Die Niederelbe. In: Land und Leute. Monographien zur Erdkunde Bd. 28, Berlin I908 (2. Auf. I913). - W. Dittmer, Hamburger Hafenbilder, Hamburg I 909. - L. Friedrichsen, Die deutschen Seehäfen, 2. Teil: Die Häfen, Lösch- und Ladeplätze an der deutschen Nordseeküste, Hamburg I 891. - Ders., Die Elbe von Helgoland bis Hamburg, Hamburg I891. - Emanuel Fitger, Schiffsbau und Seeschiffahrt in den letzten Jahren, in: Volkswirtschaftliche Zeitfragen, Vorträge und Abhandlungen, hrsg. von der Volkswirtschaftlichen Gesellschaft in Berlin, Jg. 14, H. 105, Berlin 1892-Heraux, Der Hamburger Hafen I895. Leipzig I899. - Die Freihafen-Lagerhaus-Gesellschaft I885-igio. Denkschrift zum $25 j a ̈ h r i g e n ~ J u b i l a ̈ u m, ~ H a m b u r g$ 1910. - Eckert, Die deutschen Häfen der Nord- und Ostsee, in: Nauticus Bd. 1906. - Ernst Baasch, Geschichte Hamburgs 1814-1918, 2 Bde., Gotha 1914. - Heinrich Fliigel, Die deutschen Welthäfen Hamburg und Bremen, Jena I914. - Arcbitekten- und Ingenieurverein zu Hamburg (Hrsg.), Hamburg und seine Bauten unter besonderer Berücksichtigung der Nachbarstädte Altona und Wandsbek I9I4, Bd. 2, Hamburg I9I4. - Roy Samuel MacElwee, Wesen und Entwicklung der Hamburger Hafenbaupolitik. Eine Studie der heutigen Einrichtungen des Hamburger Hafens und der Ideen, die zu ihnen geführt haben, Hamburg 191 7. E. W. O. Scbulze, Seehafenbau Bd. I, Berlin rgr I. - Hamburgs Fischerei in zehn Jahrhunderten. Vom Walfänger bis zum Fischdampfer, in: Hamburgs Heimatbücher, Hamburg I925. - Jahrbuch der Hafenbautechnischen Gesellschaft, Hamburg r9I 8 ff. - Walther Böttcher, Hamburgs Leistungen in der Volks- und Weltwirtschaft, Hamburg 1922. - L. Wendemuth, Der Hafen, in: Hamburg in seiner politischen, wirtschaftlichen und kulturellen Bedeutung. Hrsg. von der Deutschen Auslandsgemeinschaft Hamburg, Hamburg 1921, S. 33-47. - Ernst Baasch, Geschichte der Handelskammer zu Hamburg, Hamburg I9I5. - Gesellschaft der Freunde des vaterländischen Scbulund Erziebungswesens in Hamburg (Hrsg.), Der Hamburger Hafen, Hamburg 1922. - Der Hamburger Hafen, in: Hamburger Heimatbücher, Hamburg I925. - F. Franziskus und K. Bökemam, See- und Hafenbau, in: Sammlung Göschen Bd. 962, Berlin-Leipzig 1922. - Hamburger Hafen - 50 Jahre Kaibetrieb, Hamburg 1916. - L. Wendemuth und W. Böttcler, Der Hafen von Hamburg, Hamburg 1927. 
I9I4 und die Beiträge im » Jahrbuch der Hafenbautechnischen Gesellschaft" müssen als technikgeschichtliche Fundgruben angesehen werden. Kurt Wiedenfelds breitangelegter verkehrswissenschaftlicher Vergleich zwischen Hamburg und anderen nordwesteuropäischen Häfen ist ebenso wie die Arbeiten von Emanuel Fitger, Richard Ebrenberg, M. Bucbbeister, Ernst Baasch und Heinrich Fliggel bis heute lesenswert geblieben. Überall sind, vor allem in der bemerkenswerten Studie des amerikanischen Nationalökonomen Samuel Roy MacElwee über die Hamburger Hafenbaupolitik, eine Fülle historisch brauchbarer Angaben zu finden. Aber diese Schriften haben verständlicherweise heute längst Quellencharakter erhalten und sind kein Ersatz für eine Hafengeschichte aus der Feder des Historikers.

Alle seitdem erfolgten neueren Publikationen über den Hamburger Hafen dringen sehr viel weniger tief. Soweit man das bei einer ersten Durchsicht erkennen kann, untersucht die neueste Hafenliteratur entweder nur noch spezielle Teilaspekte wie die Geschichte der Kaikräne und des Freihafens oder trägt aber sehr populären Charakter ohne wissenschaftlichen Anspruch. Neuere Veröffentlichungen wie die von Friedrich Böer und Erich von Lebe oder von Bernhard Meyer-Marwitz bringen zwar eine Fülle übersichtlicher historischer Notizen und vorzügliche Abbildungen, doch sind sie offensichtlich aus Jubiläumsgründen für die breite Öffentlichkeit und aus Werbegründen geschrieben ${ }^{8}$. Gleiches läßt sich für die Schriften sagen, die von der "Gesellschaft der Freunde des vaterländischen Schul- und Erziehungswesens in Hamburg", der Behörde für Wirtschaft und Verkehr und dem Nordwestdeutschen Werbe- und Wirtschaftsverlag herausgebracht wurden. Diese schildern vor allem den Aufbau nach $1945^{9}$. Ein Beitrag zur Wissenschaft ist nicht beabsichtigt. So steht man vor dem für Historiker überraschenden Faktum,

s Friedrich Böer und Erich Lebe, 750 Jahre Hamburger Hafen. Hrsg. von der Hamburger Freihafen-LagerhausGescllschaft, Betriebsgesellschaft der Hamburger Hafenanlagen, anläßlich des Jubiläums am 7. Mai 1939, Hamburg 1939. - Bernhard Meyer-Marwitz, Hamburgs Weg zum Welthafen. Hrsg. von der Hamburger Hafen- und Lagerhaus-Aktiengesellschaft aus Anlaß der 75. Wiederkehr ihres Gründungstages 7. März I885, Hamburg I960. - Herbert Bosselmann, Die Entwicklung der Kaikrane im Hamburger Hafen bis zum Ausbruch des I. Weltkrieges unter besonderer Berücksichtigung ihrer wirtschaftlichen Auswirkung. Diss. Berlin 1935. - Walter Emmerich, Der Freihafen, Hamburg 1960. - Hans Scbröder, Hamburger Ilafenpolitik, Hamburg 1932. - O. Winter, Die Elbe. Das Ein- und Ausgangstor Deutschlands, Berlin 1934. - Scbmidt-Goertz, Der Hafen (2 Mappen mit Linoleum-Schnitten), Hamburg o. J. - A. Mablan (Hrsg.), Bunte Skizzen vom Hamburger Hafen (mit 36 Aquarellen junger Hamburger Künstler), Hamburg 1952. - Hamburg - Heimat am Strom (Sammelwerk von 33 Autoren), Hamburg 1946. - Bernbard Meyer-Marwitz (Hrsg.), Geliebter Strom. Ein Buch über die Niederelbe, Hamburg 1949. - Hamburger Freibafen-Lagerbaus-Gesellschaft (Hrsg.), Der Hafen Hamburg. Ein Handbuch für Verlader. Anläßlich des 5ojährigen Bestehens des Freihafens, Hamburg 1938. - R. Segebrecht, 225 Jahre Hamburger Hafenmühle J. P. Lange Söhne, Hamburg 1952. - Allwörden (Hrsg.), Hamburg - Dreiviertel Jahrtausend Hafen-, Handels- und Stapelplatz, Hamburg o. J. - Weniger, Industrieplanung im Niederelbegebiet. Lebensbedingungen der hamburgischen Seehafenindustrie, Hamburg 1936. - Von Fischerei und Fischmärkten in Hamburg und Altona. Hrsg. zur 50-Jahr-Feier der Fischmärkte von Altona und Hamburg, Altona 1937. - Hamburger ÜberseeJahrbuch, Hamburg 1925 ff. (enthält gelegentlich Beiträge zur Geschichte Hamburgs und seines Hafens).

- Nordwestdeutscher Werbe- und Wirtschaftsverlag (Hrsg.), Der Hamburger Hafen. Sein Wiederaufbau seit 1945, Hamburg x95 1. - Ausscbuß für Erdkunde der Gesellschaft der Freunde des vatcrländiscben Scbul- und Erziebungswesents in Hamburg (Hrsg.), Der Hamburger Hafen, Hamburg 1955. - Werner Klugmann und Walter Seeler, Hafen Hamburg I945-1965. 20 Jahre Aufbau und Entwicklung. Hrsg. von der Behörde für Wirtschaft und Verkehr, Hamburg 1965 . 
daß trotz einer beachtlichen Fülle von zeitgenössischen Darstellungen und neueren populären Einzelstudien die Geschichte des modernen Hafens, wie sie für andere Welthafenstädte bereits vorliegt, bisher noch fehlt ${ }^{10}$.

Es klingt nun weniger erstaunlich, wenn man feststellt, daß auch die Geschichte der im Hafen wirkenden Menschen, vor allem der Übergang vom zünftigen »Hafenwerker« zum industriellen Hafenarbeiter, historisch noch nicht ausreichend dargestellt worden ist. Aus Raumgründen kann an dieser Stelle aber darauf nicht näher eingegangen werden. Wie sieht nun die Vorgeschichte des modernen Hamburger Hafens aus?

\section{r. Die Hamburger Strom- und Hafenverbältnisse bis zur Mitte des 19. Jabrbunderts}

Im Rahmen einer äußerst knappen Skizze wie hier ist es nicht möglich, die Grundzüge der politischen und wirtschaftlichen Entwicklung, ja nicht einmal die Entfaltung der Handels- und Schiffahrtsverhältnisse aufzuzeigen, die mit der Entwicklung des Hamburger Hafens bis zur Mitte des vorigen Jahrhunderts untrennbar verwoben sind. Es muß an dieser Stelle genügen, einige wenige Hauptdaten aus der Geschichte der Elbregulierung und des alten Hafens anzuführen und auf die entsprechende weiterführende Literatur zu verweisen.

Wann beginnt die Geschichte des Hamburger Hafens? Wie allgemein bekannt, spielte die alte sächsische Befestigung Hammaburg bereits als Stromübergang und Grenzhandelsplatz eine Rolle, als sie zu Beginn des 9. Jhs. in die Hände der siegreichen Franken fiel ${ }^{11}$. Man nimmt heute an, daß Handel und Mission frühzeitig Hand in Hand gingen und bereits Ende des II. Jhs. ein Fernhandel bestand. Anscheinend wurde jedoch im I 2. Jh. erkannt, daß dieser abgelegene Ort im Sumpf- und Inselgebiet der Alstermündung zugleich eine von Natur aus geschaffene Grenze zwischen der See- und Flußschiffahrt auf der Elbe bildete. Mit dem Willen, sich die Elbemündung dienstbar zu machen, beginnt Hamburgs Aufstieg zum Hafen ${ }^{12}$. Die Gründung des Hamburger Hafens wird von der Forschung übereinstimmend etwa um das Jahr i i 89 angenommen, als der Landesherr Graf Adolf III. von Holstein aus dem Haus der Schauenburger anläß-

${ }^{10}$ Vergl. z. B. Sir David Oven, The Origin and Development of the Ports of the United Kingdom, 2nd rev. edition, London 1948. - Sir Joseph Broodbank, History of the Port of London, 2 vols., London 1921. - Walter $M$. Stern, The First London Dock Boom and the Growth of the West India Docks, in: Economia New Series vol. I 9 (1952). - Suart Mountfield, Western Gateway. A History of the Mersey Docks and Harbour Board, Liverpool 1965. - D. Swann, The Pace and the Progress of Port Investment in England 1660-1830, in: Yorkshire Bulletin of Economic and Social Research (Hull), vol. 1960, pp. 32-44. - Hermann Scbumacher, Antwerpen. Seine Weltstellung und Geltung für das deutsche Wirtschaftsleben, München-Leipzig 1916. - Van Ravesteyn, Rotterdam in te 19. eeuw., Rotterdam 1924. - Rotterdam in den loop der eeuwen, 2 Bde. Rotterdam 1906-1 908. - Paul Arndt, Antwerpen, Rotterdam und die deutsche Rheinmündung, Stuttgart i918. - SVZ (Hrsg.), Stand van zaken. Gedenkboek bij het vijftigjarig bestaan der Scheepvaart Vereening Zuid (SVZ), Rotterdam I957.

${ }^{11} B$. Weißenborn, Die Elbzölle und Elbstapelplätze im Mittelalter, Halle rgor. - A. Wieske, Der Elbhandel und die Elbhandelspolitik bis zum Beginn des 19. Jahthunderts, Halberstadt 1927. - Treutler, Hamburgs Handelsverkehr im Mittelalter, in: Hamburgs Ubersee-Jahrbuch Jg. I925, S. 332.

12 W. Stein, Beiträge zur Geschichte der deutschen Hanse bis zur Mitte des I 5. Jahrhunderts, Gießen I900. Bäcbthold, Der norddeutsche Handel im I2. und beginnenden I3. Jahrhundert, Hamburg 1908, S. I63 ff. 
lich der Verleihung der Stadtrechte für die Neustadt Hamburgs den Bau eines Hafens an der Alstermündung (an der Stelle des heutigen Nicolaifleet) einem später urkundlich als Ratsmann erwähnten Wirad von Boizenburg übertrug und Kaiser Friedrich I. Barbarossa u. a. Zoll- und Abgabenfreiheit sowie die Fischereirechte auf der Niederelbe gewährte ${ }^{13}$. Aufgrund von Eindeichungen des Alstertiefs erweiterten sich die Grenzen der Stadt so, daß eine erste Hafenfläche entstand. Durch Verträge mit den umliegenden Marschländern Hadeln und Wursten sowie den Dithmarschern und Strandfriesen wurde eine Milderung des alten an der gesamten Nordsee geltenden Strandrechts, demzufolge bei Schiffbruch angetriebene Güter den Küstenbewohnern zukamen, erreicht und als Gegenleistung die Ausfuhr von Agrarprodukten aus diesen Gegenden über Hamburg abgabemäßig erleichtert. Durch Abmachungen mit Handelsplätzen am Niederrhein, in Holland, Flandern und Brabant, Einführung von dem Fernhandel dienenden Jahrmärkten und der lübisch-hamburgischen Mark, die zum gebräuchlichsten Zahlungsmittel der Hanse wurde, blühte der Verkehr so empor, daß I 258 erste hafenbauliche Verbesserungen vorgenommen werden mußten, indem durch eine künstliche Verbindung zwischen Alstermündung und Bille (dem heutigen Zollkanal) eine bessere Durchspülung und Vertiefung des Alsterbinnenhafens erreicht wurde.

Auch die weitere Entwicklung ist so bekannt, daß man sich auf wenige Andeutungen beschränken kann: Für die nächsten Jahrhunderte führte die kürzeste Verbindung zwischen dem agrarischen Osten zu den Märkten Westeuropas über Lübeck, da die Sunddurchfahrt zu gefährlich war. Hamburg verstand es geschickt, als »Nordseehafen Lübecks" (Walter Vogel) sich in die große Ost-West-Handelslinie mit seinen zahlreichen Verzweigungen einzuschalten und alle benachbarten Handelsplätze wie Lüneburg, Stade und das alte Bardowiek weit hinter sich zu lassen ${ }^{14}$. Nach London, wo 1286 der englische König hamburgischen Kaufleuten das Recht der »Hanse«, d. h. zur Niederlassung einer lokalen Kaufmannsgenossenschaft einräumte, nach Skandinavien und an die atlantische Küste Südeuropas dehnte sich Hamburgs Handel im I 3. und I 4. Jh. aus. Das I 270 im »Ordeelbok" gemeinsam für die Alt- und Neustadt niedergelegte Stadtrecht enthielt erstmals in Deutschland auch schiffsrechtliche Bestimmungen, die bei der Neufassung der Stadtrechte I306 erweitert wurden. 1286 erwirkte sich die Stadt das Recht, zur Sicherung seiner Schiffahrt auf der Insel Neuwerk in der Elbmündung als Seezeichen einen Turm zu errichten ${ }^{15}$. ${ }_{3} 65$ war der Verkehr auf der Elbe so ansehnlich, daß in den »Burspraken« (Ratsverordnungen) besondere Vorschriften hierfür erlassen werden

${ }_{13}$ Lebe, Heimatchronik, 2. Auf., S. 39 ff. - Wendemutb-Böttcber, Hamburgs Hafen S. I 5. - Heinricl Reincke, Hamburgische Territorialpolitik, in: Zeitschrift des Vereins für Hamburgische Geschichte Bd. 38 (1939), S. 29. Nebls-Bubendey, Elbe a. a. O. S. 13/14.

14 Walther Vogel, Kurze Geschichte der deutschen Hanse, München-Leipzig I9I s. - Dietrich Scbäfer, Die deutsche Hanse, 2. Auf. Bielefeld-Leipzig 1925. - Ernst Daenell, Die Blütezeit der deutschen Hanse, 2 Bde., Berlin 1905/06. - Fritz Rörig, Hansische Beiträge zur Wirtschaftsgeschichte, Breslau 1928. - Karl Pagel, Die Hanse, 2. Aufl. Oldenburg 1952. - Städtewesen und Bürgertum als geschichtliche Kräfte (Gedächtnisschrift für Fritz Rörig), Lübeck I953. - Erich von Lebe u.a., Hamburg und die deutsche Hanse, Hamburg 1939.

${ }_{15}$ Entgegen älteren Forschungen scheint jetzt festzustehen, daß noch nicht in der Hansezeit, sondern erstmals 1648 auf dem Neuwerker Turm ein von Steinkohlen unterhaltenes Leuchtfeuer auf einer hölzernen »Blüse" (Gerüst) brannte. Der Grund, weshalb man so relativ spät mit einem Leuchtfeuer an der Elbmündung begann, 
mußten. Auf dem Höhepunkt hansischer Macht konnte das Amt Ritzebüttel I395 erworben und dort Cuxhaven als Not- und Lotsenhafen ausgebaut werden ${ }^{16}$. Schon frühzeitig machte Hamburg auch erhebliche Aufwendungen zur Eindeichung der Marschen und Uferbefestigung; wichtiger erwries sich jedoch die Absperrung einzelner Elbearme (Gose- und Dove-Elbe) im I 5. Jh., um dem Hauptstrom mehr Wasser zuzuführen. Zwischen I 568 und 1650 wurden mehrere Elbinseln durchstochen und ver-

dürfte darin zu suchen sein, daß die Schiffe wegen der weit herausragenden Sandbänke nicht dicht genug an die Küste heranfahren konnten. Außerdem war es jahthundertelang nicht üblich, nachts zu segeln. Die Schiffe pflegten Helgoland anzulaufen und erst bei Tage in die Elbe zu kommen. Ein weiterer Hinderungsgrund dürfte aber auch gewesen sein, daß die in Eisenkörben brennenden Steinkohlen unvergleichlich teuer waren, anderes Brennmaterial sich aber nicht zur Befeuerung eignete. Der erste Leuchtturm in der Deutschen Bucht wurde wahrscheinlich 1602 mit Öllampen auf der Insel Wangerooge errichtet, damit die Grafen von Oldenburg ihre Zollabgaben besser erheben konnten. Die erste dauernde »Feuerbake« entstand $16_{3} O$ auf Helgoland gegen den Widerstand der Einwohner, die einen Rückgang ihrer Einnahmen aus den Strandungen befürchteten. Eine wirkliche Funktion als nächtliche Seezeichen erfüllten die Leuchttürme erst am Ende des I 8 . Jahrhunderts, als die Argandsche Öllampe und der Spiegelreflektor erfunden worden waren. Ein Leuchtturm dieser Art wurde I 8I I in Cuxhaven, das erste durch ein Uhrwerk berwegte Dreh- oder Blinkfeuer kurz danach auf Wangerooge errichtet. Die hamburgische Insel Neuwerk verfügt seit I 8 I4 über einen Leuchtturm mit Argandschen Lampen und Parabolspiegeln. Vergl. folgende Literatur über die Geschichte des Leuchtfeuers: $A$. W. Lang, Entwicklung, Aufbau und Verwaltung des Seezeichenwesens an der deutschen Nordseeküste bis zur Mitte des I9. Jahrhunderts, Bonn r965. - K. Ferber, Der Turm und das Leuchtfeuer auf Neuwerk, in: Zeitschrift des Vereins für Hamburgische Geschichte Bd. I4 (1909), S. I ff. - Ders., Das Leuchtfeuer auf dem Hohen Sande, in: ebd. Bd. I6 (Igr I) S. 86 ff. - K. Fissen, Der Westturm von Wangerooge im Wandel der Zeiten, Oldenburg 1932. - P. Griibeler, Die Betonnung und Befeuerung der Elbe durch Hamburg, in: Jahrbuch der Hafenbautechnischen Gesellschaft Bd. Io, Hamburg I929. - G. Jacoby, Aus der Geschichte der Leuchtfeuer und Seezeichen, eine Einführung in die Literatur, Kiel I929. - L. A. Veitmeyer, Leuchtfeuer und Leuchtapparate, hrsg. von Max Geitel, MünchenLeipzig 1900. - J. H. Stalling, Die Leuchtthürme an der Nordseeküste Deutschlands, Oldenburg I825. - M. Bucblbeister und E. Bensberg, Hamburgs Fürsorge für die Schiffbarkeit der Unterelbe, Hamburg r gor. - DomkeEngels, Verzeichnis der Seeleuchten aller Meere, 3 Bde., Berlin 1873.

16 Die Entwicklung des Hamburger Trabantenhafens Cuxhafen muß hier ebenfalls außer Betracht bleiben. Vergl. Gerbard Lüssow, Cuxhaven als Vorhafen von Hamburg, Diss. Rostock 1936. - Dietrich Mende, Politik und Wirtschaft im Kampf um das Unterelbe-Gebiet Bd. I, Teil I, Hamburg I925. - Guido Möring, Cuxhaven als Fischereihafen und Fischmarkt, Hamburg I935. - Heinrich Reincke, Das Amt Ritzebüttel, Diss. Hamburg 1935.- Reinbard Woltmann, Geschichte und Beschreibung der Wasserbauwerke im Amt Ritzebüttel, Hamburg 1807. A. Hagedorn, Gedenkblatt zur Feier der 500jährigen Vereinigung des Amtes Ritzebüttel mit der Freien und Hansestadt Hamburg, Hamburg I 894. - 200 Jahre Wasserbauverwaltung in Ritzebüttel-Cuxhafen. Hrsg. vom Hafenund Verkehrsamt Cuxhafen, Cuxhafen I95x. - Heinz Wacbtendorf, Die Stadt Cuxhaven, in: Die Stadt Cuxhaven und der Landkreis Hadeln, Oldenburg i. O. I961. - Paul Volquart, Hamburgs Territorialpolitik in der Vergangenheit, Kiel 1922. - Walter Höpcke, Wie Cuxhafen eine Stadt wurde, Cuxhafen 1955. - Eduard Heymann, Hafenbauten in Cuxhafen, in: Hamburg und seine Bauten 1914, Hamburg 1914. - Joachim Hermann, Die Erwerbung des Amtes Ritzebüttel durch Hamburg, in: Zeitschrift des Vereins für Hamburgische Geschichte Bd. 9 (I 906). A. Abendroth, Beschreibung des Fahrwassers nach und in der Mündung der Elbe, Hamburg I860. - Ders., Ritzebüttel und das Seebad Cuxhafen, 2 Theile, Hamburg I818-1837. - F. A. Becker, Cuxhaven und das Amt Ritzebüttel, o. O. I880. -J. F. Bubendey, Der neue Hafen von Cuxhaven, Hamburg 1904. - Otto Lack und Hermann Selmer, Der Ausbau des Fischereihafens Cuxhafen, in: Jahrbuch der Hafenbautechnischen Gesellschaft Hamburg Bd. $27 / 28$ (1962/63). - Ernst Albers, Das Deichrecht im Amte Ritzebüttel, Leipzig 1938. - H. Lenz, Der neue Hafen von Cuxhafen, Berlin ז 898. - Erich von Lelbe, Handel und Schiffahrt zwischen Hamburg und Land Wursten in sieben Jahrhunderten I238-1938, in: Jahrbuch der Männer vom Morgenstern Bd. 3r, Neuhaus/Oste 1948 . 
sandete Elbarme abgeriegelt, wodurch die Norderelbe überhaupt erst künstlich geschaffen und der Strom ganz nahe nun an Hamburg herangeführt wurde. Die I 2 Meter lange und ein Meter hohe Panoramakarte des Flensburger Malers Melchior Lorichs, die dieser im Auftrag des Hamburger Rats I 568 zeichnete, läßt den damaligen Zustand der Elbe von Geesthacht bis Neuwerk mit allen Einzelheiten und sogar den Seezeichen erkennen ${ }^{17}$.

Als Seezeichen dienten zuerst wohl markante Küstenpunkte wie Türme und Baumgruppen. Der Kirchturm von Pellworm, Schloß Ritzebüttel, der Doppelturm von Altenbruch und die Nikolaikirche von Wangerooge sowie natürlich der Neuwerker Turm (zugleich ein militärischer Stützpunkt Hamburgs) waren solche Landmarken, die auf Seekarten des r6. Jahrhunderts schon eingezeichnet waren. Das Fahrwasser im Watt, die Priele, wurden wie heute noch mit jungen Baumstämmen bezeichnet, die mit der Zeit Körbe oder Fässer als Toppzeichen zur besseren Unterscheidung bekamen und dann "Kopfbaken" genannt wurden. Sie wurden auch auf dem Lande verwandt, wie Melchior Lorichs' Elbekarte zeigt. In der 2. Hälfte des 16 . Jahrhunderts ging man, wie die Hamburger Kämmereirechnungen belegen, zu großen Gerüstbaken über. Die erste wurde auf Scharhörn in der Elbmündung errichtet. Eine Reihe fester Baken (Alte Bake, Roßbake, Klapmützenbake usw.) ist seitdem trotz Sturm und Wasserflut ständig beibehalten worden. Die Seetonnen sind eine Schöpfung des Mittelalters und wahrscheinlich sogar in der Nordsee zuerst aufgekommen. Erste Nachrichten stammen aus dem I 2. Jahrhundert. Bereits 1477 scheint Hamburg eine planmäßige jährliche Vertonnung der Elbe durchgeführt zu haben. Auf Melchior Lorichs' Elbkarte sind i 8 Tonnen zu erkennen, die meistens an größeren Sänden oder den Mündungen kleiner Nebenflüsse lagen. I66r wurden die ersten Seetonnen verlegt: die »Rote Tonne«, I 664 die »Bremer Schlüsseltonne«. War zunächst nur die rechte Elbseite betonnt, so begann man nach I65o auch die linke Fahrwasserseite abzugrenzen. Zur besseren Unterscheidung wurden dann schwarze und weiße Tonnen ausgelegt. Die Schiffer gaben den Tonnen Spitznamen, die auch noch beibehalten wurden, als die Tonnen numeriert wurden. Für die Rückgabe verlorengegangener Seetonnen, die in der Anschaffung sehr teuer waren und alle das Hamburger Wappen trugen, wurde als Bergelohn oft ein Faß Bier, eine Tonne Salz oder ıo Reichstaler gezahlt, was oftmals dazu führte, die Tonnen mutwillig aus der Verankerung zu lösen. Dies wurde dann schwer bestraft, in Bremen sogar einmal mit dem Tode. Um 1750 war die Betonnung der Elbe schon so dicht, daß man von der einen die andere Tonne sehen konnte. Am Ende des I8. Jahrhunderts wurde die Betonnung allgemein schon als ausreichend angesehen ${ }^{18}$.

17 Einen Ausschnitt dieser Karte zeigt Böer, 750 Jahre Hamburger Hafen, S. I9. - Vergl. Johann Martin Lappenberg, Die Elbkarte des Melchior Lorichs vom Jahre is 68, Hamburg 1847.

18 Über die Entwicklung der Landmarken und Seetonnen in der Elbe unterrichten u. a.: Lang, Seezeichenwesen a. a. O., S. 18 ff. - Jacoby, Leuchtfeuer und Seezeichen a. a. O., S. 22 ff. - A. Hops, Über die Entwicklung des Seezeichen- und Befeuerungswesens bis zum internationalen Betonnungssystem, in: Die Wasserschutzpolizci Jg. 5 (1953), Folge 8. - Erich von Lebe, Ein Turm und seine Insel. Neuwerk im Strom der Zeiten, Cuxhafen 1952. - K. Ferber, Die Entwicklung des Hamburgischen Tonnen-, Baken- und Leuchtfeuerwesens, in: Zeitschrift des Vereins für Hamburgische Geschichte Bd. I8 (I9I4). - Grïbeler, Betonnung und Befeuerung der Elbe a. a. O., S. I 73 ff. 
Das I7. Jh. brachte $z$ wischen 1616 und I 625 die vielleicht wichtigste Hafenerweiterung vor dem 19. Jh., als Hamburg zur stärksten Festung Norddeutschlands ausgebaut und durch Anlage verschiedener Bastionen beim Grasbrook und des Johannisbollwerks mit der Verlegung des »Niederbaums« eine bedeutende Erweiterung der umgrenzten Fläche des Alsterbinnenhafens erzielt wurde. Nach dem Einsatz einer "Düpe-Commission" konnte darin die frühere Tiefgangbegrenzung aufgehoben werden ${ }^{19}$. Zur allgemeinen Beförderung der Schiffahrt entstand nach holländischem Beispiel ein »AdmiralitätsCollegium«, während Streitigkeiten zwischen Kapitän und Schiffsvolk vor dem »Wasserschout « ausgetragen wurden, wo gleich dem heutigen Seeamt auch die An- und Abmusterungen erfolgten. $16_{3} 6$ erließ der Rat die erste Instruktion für den Hafenmeister, dem schon lange vorher die Aufsicht über den Schiffsverkehr und die Zollabgaben übertragen worden war.

Die Zahlen über den Hamburger Schiffsverkehr sind zunächst schwer zu ermitteln ${ }^{20}$. Gelegentliche Angaben in den Zollregistern sind ungenau und kaum miteinander vergleichbar. Anläßlich der englisch-holländischen Seekriege im späten I 7. Jh. entstanden zwar erste vollständige Schiffslisten in Hamburg, um die Identifizierung der neutralen Hamburger Schiffe zu erleichtern und sich besser vor den Kapern zu schützen. Danach hätte 1672 Hamburg über 277 Schiffe mit 21 260 Last verfügt. Beim Beginn der eigentlichen Hamburger Schiffsstatistik r765 waren es aber nur 85 Schiffe mit 8890 Last. Da trotz aller konjunkturellen Schwankungen ein solcher Rückgang des Schiffsverkehrs unwahrscheinlich ist, kann nur der Schluß daraus gezogen werden, daß die frühe Schiffsstatistik zahlreiche Fehlerquellen enthält, u. a. fuhren viele Hamburger Schiffe unter fremder Flagge ${ }^{21}$. In all dieser Zeit hatte Hamburg auch mit vielen, Handel und Schiffahrt hemmenden Schwierigkeiten zu kämpfen, so z. B. dem Zoll des Glückstädter Konkurrenzhafens, mit den Seeräubern und Kapern (gegen die besondere Konvoischiffe gebaut wurden), mit den Belagerungen durch fremde Truppen und schließlich der englischen Navigationsakte. Im frühen r 8. Jh. setzte man, da Hafen und Fahrrinne 19 Die unter dem Ratsherm Dietmar Koel eingesetzte "Düpe-Commission" hat den Verdienst, den Naturhafen erstmals wesentlich verbessert zu haben. Auch die Betonnung der Elbe geht wesentlich auf ihre Tätigkeit zurück. Eine Tonne wurde zu Ehren dieses Ratsherrn benannt. Die Beamten dieser Kommission hatten den Namen "Fleetenkieker".

${ }^{20}$ Die Schiffahrtsstatistik vor der Mitte des I8. Jahrhunderts ist überhaupt ein schwer erforschbares Gebict. Die aus Zollregistern oder gelegentlichen örtlichen Zählungen stammenden Angaben sind unvollständig und untereinander nicht vergleichbar. So wurden die in Ballast fahrenden Schiffe, weil sie nichts zu verzollen hatten, nicht mitgezählt, andere dagegen in einer Zählperiode mehrfach. Auch fehlte es zunächst an der heute üblichen Trennung zwischen See-, Küsten- und Flußschiffen. Manche Einheiten, die im Berichtszeitraum länger abwesend waren, wurden manchmal gar nicht aufgeführt. Wegen der zahlreichen Fehlerquellen lassen sich vor dem Siebenjährigen Krieg nur einige wenige Trends konstruieren, deren Bedeutung nicht überschätzt werden darf. Vergl. Walther Vogel, Die Grundlagen der frühen Schiffahttsstatistik, Berlin I gr I. - Ders., Zur Größe der curopäischen Handelsflotten im Is, 16., und 17 . Jahrhundert (Dietrich Schäfer-Festschrift), Jena 1915. - Ralph Davies, The Rise of the English Shipping Industry in the Seventeenth and Eighteenth Century, London I962.Hans Jürgen Teuteberg, Die Industrialisierung der britischen Seeschiffahrt in deutschen Augenzeugenberichten zwischen 1750 und I 850, in: Technikgeschichte Bd. 34 (1967), S. 226-264.

${ }^{21}$ Die z.Zt. beste Untersuchung über das Wachstum der Hamburger Handelsschiffahtt seit dem Siebenjährigen Krieg ist die von Walter Kresse, Materialien zur Entwicklungsgeschichte der Hamburger Handelsflotte 1765 bis 1823, Hamburg 1966. (Vergl. dort besonders S. 67 ff.) 
mal wieder völlig zu versanden drohten, zur Verbesserung der Stromverhältnisse auf der Niederelbe und im Binnenhafen eine besondere »Elbedeputation« ein, der außer den Hamburger »Oberalten« auch Kaufleute und Schiffsführer angehörten ${ }^{22}$. Im 17. Jh. wurden wegen der sich häufenden Unglücke erstmals ein Lotsenzwang eingeführt und I $73 \mathrm{I}$ das Versicherungsrecht in der "Assecuranz- und Havarie-Ordnung" einheitlich geregelt $^{23}$. Auch das Seekartenwesen wurde vervollkommnet. Durch den Abfall der englischen Kolonien in Nordamerika begann ein erster bedeutender Aufschwung des Hamburger Hafens nach der Hansezeit. Der Schiffsverkehr nahm

${ }^{22}$ In einer Resolution vom 7. Februar I7I g heißt es über die Stromverhältnisse wörtlich: „E. E. Rat hat es für nötig gehalten, den Elbstrom und seine Untiefen durch eine besondere Deputation aus seiner Mitte, der Erbgesessenen, Oberalten, der Verordneten der löblichen Cämmerey und der Commercii untersuchen zu lassen. Deputatio Commercii bringen häufig Klagen vor, daß auf ihre vielfältige Aufforderung und Verbesserung der Dinge sowohl in der Stadt als auf der Elbe nicht geachtet worden und stellt vor, daß wenn man auch nicht aufs schleunigste noch vor dem Winter zur Sache tue, die Elbe sich völlig zuschlingen würde.«Zitiert nach MacElwee, Hamburger Hafenbaupolitik S. 6 .

${ }^{23}$ Nach Lappenbergs Ansicht sprechen schon die ältesten Hamburger Schiffstechte um I 300 von einem "Lodemann" oder "Lietsagen", der dafür bezahlt wurde, um die Einfahrt in den Strom zu weisen. Wahrscheinlich haben Elbefischer dieses Amt zuerst auf eigene Faust ausgeübt. Nach W. Vogel soll es 1447 bei der Hanse bereits einen Lotsenzwang gegeben haben, doch bestand dieser wahrscheinlich nur auf dem Papier. Gegen Ende des 16. Jahrhunderts waten mit Sicherheit auf der Insel Neuwerk bereits mehrere Elbelotsen ansässig, die aber nebenbei noch Fischerei betrieben. Anfang des 17. Jahrhunderts wurden einige »Piloten« von dem Rat der Stadt Hamburg vereidigt bzw. als Hafen- und Schleusenmeister in Ritzebüttel angestellt. Nachweislich ist durch ein Mandat am 28. Oktober I639 aufgrund der sich häufenden Unfälle der Lotsenzwang erstmals in den Wintermonaten fest eingeführt worden. Danach hatte auch derjenige eine feste Lotsengebühr von 5 Talern zu zahlen, der keinen Lotsen nahm. Ohne Lotsen hatte der Schiffsführer sonst für alle Schäden zu haften. Nachdem I655 dennoch vier reich beladene Schiffe verunglückt waren, wurden ein Jahr später zwei eigene Lotsengaliotten angeschafft und nach holländischem Vorbild eine 17 Artikeln umfassende Lotsenordnung publiziert. Danach hatten zwei Lotsenboote ständig vor der Elbmündung zu kreuzen und ankommende Schiffe mit Lotsen zu verschen. Die Lotsen wurden von der Hamburgischen Admiralität vorher geprüft und nach Tarif bezahlt. Diese Ordnung blieb bis I 8 Io bestehen. Die hamburgischen Lotsen, die in der Regel sechs Jahre Praxis auf der Elbeschiffahrt hatten, übernahmen beim Betreten des Schiffes die Funktionen des Kapitäns. Das Lotsengeld wurde nach dem Tiefgang des Schiffes berechnet, was natürlich dazu führte, den Tiefgang niedriger anzugeben, um die Gebühr zu ermäßigen. Der Lotse hatte kein leichtes Amt, da et bei einem Unglück abgesetzt wurde und ins Gefängnis $\mathrm{kam}$. Verweisung oder Strafen am Leibe waren nicht selten. Zur Aushilfe bei starkem Verkehr gab es daneben sog. Heuer- oder Beilotsen. Insgesamt schwankte die Zahl der Elbelotsen immer zwischen ro und 16 bzw. bei den Aushilfen zwischen 5 und I 5 . Die Helgoländer Lotsen, die nicht staatlich geprüft waren, hatten keinen guten Ruf. Sie betrieben das Lotsenwesen als freie Jagd und stürzten sich auf jedes Schiff, das sich der Insel näherte, da mit dem Lotsendienst viel mehr als mit der Fischerei zu verdienen war. Später wurde die »freie Fahrt« durch die geordnete "Börtfahrt» ersetzt, d. h. es fuhr jeweils nur eine Schaluppe mit einem Lotsenoffizier der Reihe nach abwechselnd hinaus. Aber auch die Blankeneser Fischer segelten als dänische Untertanen gern hinaus und machten den Hamburgern und Helgoländern hier Konkurrenz. I 804 mußten besondere Verordnungen gegen das Lotsenunwesen erlassen werden. Als Helgoland englisch geworden war, wurde durch gemeinsames Vorgehen von Dänemark, Hannover und Hamburg das Elbelotsenwesen endgültig geordnet, während es auf Helgoland immer mehr verkümmerte. Am Ende des I9. Jahrhunderts besaß Hamburg schon mehrere große Lotsendampfer, die die Lotsen zu den Elbefeuerschiffen und den ständig kreuzenden Lotsenschonern brachten. Vergl. $K$. Ferber, Das hamburgische Lotsenwesen auf der Unterelbe bis zum Jahre 1810, Cuxhaven 1901. - E. Römer, Zur Geschichte des niedersächsischen Lotsenwesens, in: Der Seewart, H. 3-4, Hamburg I940. - F. Dannmeyer, Seelotsen-, Leucht- und Rettungswesen, Leipzig I gr r. - Bucbbeister-Bensberg, Hamburgs Fürsorge für die Schiffbatkeit der Unterelbe a. a. O. 
innerhalb kurzer Zeit einen solchen Umfang an, daß die Liegeplätze erstmals im Alsterbinnenhafen nicht mehr ausreichten und außerhalb im freien Elbestrom durch eine Reihe von Pfahlbündeln, den Dückdalben, weiterer Hafenraum geschaffen werden mußte. I795 wurde schon eine zweite Reihe solcher Dückdalben verankert ${ }^{24}$. Um I 800 umfaßte der neue »Rummelhafen« auf der Elbe und der alte umgrenzte »Niederhafen» zusammen 16,5 ha. Außerdem gab es noch einen »Oberhafen « für die Elbkähne und einen Holzhafen vor dem Grasbrook. Daneben existierte der damals recht bedeutende Altonaer Hafen, in dem zeitweise mehr Schiffe als in Hamburg registriert waren ${ }^{25}$. Nach dieser großen Blüteperiode zwischen 1783 und 1799 , in der die Hamburger Schifffahrt unter eigener Flagge erstmals nach Nordamerika, Westindien, Ostindien und China erweitert werden konnte, folgte die ebenso tiefe Handelskrisis, gefolgt von Elbblockade und Kontinentalsperre sowie schließlich die Besetzung der Stadt durch die Franzosen, wodurch Handel und Schiffahrt fast ganz zum Erliegen kamen bzw. vom benachbarten Tönning aus mühsam und heimlich weiterbetrieben werden mußten ${ }^{26}$.

Das I9. Jh. brachte dann nach dem Wiener Kongreß symbolisch eine endgültige Abkehr vom Mittelalter, als die alten Festungsanlagen geschleift wurden ${ }^{27}$. Aber bis 1860 blieb es weiterhin bei der alten Torsperre. Bis zur Mitte des 19. Jh. waren Straßenreinigung und Beleuchtung genauso kümmerlich wie in den Jahrhunderten zuvor. Die Abwässer flossen in der Mitte der Straße in einem Rinnstein in die Fleete, aus dem auch die Trinkwasserversorgung mit Hilfe privater »Wasserkünste« geschah. Mit dem Schritt ins moderne Zeitalter hatte es, wie man aus solchen Details ersehen kann, noch gute Weile. Hamburg wollte und konnte sich nicht mehr selbst verteidigen und suchte Anschluß.

${ }_{24}$ Dückdalben sind eine Reihe von Baumstämmen, die in den Flußgrund eingerammt und eng miteinander verbunden werden. Diese Pfahlgruppen liegen in Keihen so dicht beieinander, daß ein Schiff bequem daran festmachen kann. Woher diese Bezeichnung stammt, ist noch ungeklärt. In den älteren Schriften des I9. Jahrhunderts findet sich die Schreibweise Dückdalben, Duckdalben und sogarDuc d'Alben. Erst seit I 9 I I ist der Name Dückdalben für eine Verbindung von drei Pfählen zum Schiffsanlegen amtlich verbindlich geworden. Wahrscheinlich kommt der seltsame Name nicht vom Herzog von Alba, sondern von der Bezeichnung "Dikdollen", d. h. von den Dollen (Baumstämmen), die vor dem Dik (Deich) angebracht waren.

${ }_{25}$ Auch die Geschichte des Altonaer Hafens muß hier aus Raumgründen außer Betracht bleiben. Vergl. folgende weiterführende Literatur: Richard Ehrenberg, Das Königliche Kommerz-Collegium Altona, Altona 1892. - Ludwig Brinner, Die deutsche Grönlandfahrt, Berlin r913. - Berend Carl Rosen, Geschichte unseres Hauses, Altona I892. - Axel Nielsen, Dänische Wirtschaftsgeschichte, Jena 1933. - Hans Ehlers, Aus Altonas Vergangenheit, Altona 1926. - Heinz Mïnte, Das Altonaer Handlungshaus van der Smissen 1682-1824, Altona I932. Hans Berlage, Altona. Ein Stadtschicksal. Von den Anfängen bis zur Vereinigung mit Hamburg, Hamburg 1937. - Hinrich Kloth, Altona in Vergangenheit und Gegenwart, Hamburg 195 I. - Friedrich Marwedel, Festschrift zur 200Jahr-Feier des Commerz-Collegiums am I9.1 2.1938, Hamburg 1938.- E. H. Wichmann, Geschichte Altonas unter Mitwirkung eines Kenners der vaterstädtischen Geschichte, Altona I885. Agathe Wucher, Die gewerbliche Entwicklung der Stadt Altona im Zeitalter des Merkantilismus 1664-I 808, Diss. Hamburg I955.

${ }^{26}$ Vergl. Adolf $W$ oblwill, Neuere Geschichte der Freien und Hansestadt Hamburg, insbesondere von 1789 bis I815, Gotha I914. - Ders., Hamburgs Beiträge zur Geschichte der Jahre I798-99. In: Zeitschrift des Vereins für Hamburgische Geschichte Bd. 7 1908. - Jobann Georg Büsch, Versuch einer Geschichte der Hamburgischen Handlung, Hamburg 1797. - Ernst Baasch, Hamburgs Handel und Schiffahrt am Ende des I 8. Jahrhunderts, in: Hamburg um die Jahrhundertwende I800, Hamburg 1900. - Ders., Beiträge zur Geschichte der Handelsbeziehungen zwischen Hamburg und Amerika, in: Festschrift der Hamburg-Amerika-Feier, Hamburg 1892.

27 Griese, Hamburger Hafen a.a. O., S. I 8. 
I8I 5 wurde die Stadt selbständiges Mitglied des Deutschen Bundes und nannte sich fortan »Freie und Hansestadt«. Mit aller Kraft wandte man sich aber weniger der Reform der politischen Verfassung zu, wo alles vorläufig auf den alten Gleisen weiterlief, als vielmehr der Förderung des »allzeit gelobten Commerciums«. Eines der schwersten Hindernisse waren hier die Elbzölle. I8 2 I schloß Hamburg mit den Elbanliegerstaaten die »Elbschiffahrtsakte«, wodurch 35 Zollämter an der Elbe auf 14 reduziert wurden. Diese wurden erst 1858 endgültig aufgehoben. Auch fiel dann I86 I durch einen Vertrag mit dem Königreich Hannover der schon seit Barbarossas Zeiten bestehende Stader Zoll für die nichthamburgische Schiffahrt, und 1870 war nach einem Entscheid des Norddeutschen Bundes der ganze Elbestrom erstmals in Deutschland zollfrei. Nicht zufällig fällt der Beginn des modernen Hamburger Hafens mit diesem Datum zusammen.

Welche signifikanten Faktoren haben nun, so muß nach dieser einleitenden kurzen Übersicht gefragt werden, die Industrialisierung des Hamburger Hafens im einzelnen beflügelt oder sogar erzwungen? Zunächst ist hier die bekannte Tatsache anzuführen, daß sich zu Beginn der zwanziger Jahre die lateinamerikanischen Kolonien von den Mutterländern lösten und der internationalen Schiffahrt öffneten. Auch England lockerte, durch diese Ereignisse gewarnt, seine kolonialen Handelsprivilegien. Zwar blieb die berüchtigte Navigationsakte, die den Verkehr mit den Kolonien weitgehend englischen Schiffen vorbehielt, noch bis zur Mitte des Jhs. bestehen, wurde aber zunehmend mehr durchlöchert. London war noch die größte Hafenstadt Europas, büßte aber seine Monopolstellung endgültig ein. Zögernd begannen die anderen Seestädte unter Hamburgs Führung ihre überseeischen Positionen auszubauen. Handelsverträge mit der Neuen Welt, wo überall erstmals Konsulate errichtet wurden, öffneten Deutschland neue Absatzgebiete. Bremen eroberte sich im Nordamerika-, Hamburg im Südamerikahandel eine Spitzenposition. Auch die einsetzende Auswanderung nach Übersee hatte eine nicht zu unterschätzende Wirkung auf den Aufschwung der deutschen Seeschiffahrt und ihrer Hafenanlagen. Während im ganzen I 8. Jh. nur etwa 200000 Deutsche nach Amerika gingen, verließen zwischen 1820 und I9I 3 etwa 5,5 Mill. Menschen Deutschland. Es gibt keinen Zweifel mehr (nach Wätjens und Beutins Forschungen), daß insbesondere die Auswanderertransporte das Rückgrat des ersten deutschen Nordatlantikvcrkehrs gewesen sind. Durch ihr »lebendes Gut« waren die deutschen Reeder in der Lage, ihre Rückfracht in Baumwolle und Tabak besonders niedrig zu kalkulieren und die amerikanische Flagge nahezu ganz auf dieser Route zu verdrängen. Zwar war Bremen anfangs sehr viel stärker als Hamburg am Auswandererverkehr beteiligt, doch übte dieser nach I 836 einen immer stärker werdenden Einfluß auch auf den Hamburger Verkehr aus, wie die Vergleiche der Auswandererzahlen ganz exakt beweisen ${ }^{28}$. Schließlich kam der Ausbau des Binnenwasserstraßennetzes und det Eisenbahnen hinzu. Dadurch, daß ${ }_{28}$ Die deutschen Auswanderströme setzten bekanntlich im großen Stil auf dem Höhepunkt der Agrarkrisc I 816/17 ein, als während eines Jahres 20000 Menschen vor allem aus Südwestdeutschland nach Amerika gingen. Bis zur Mitte des 19. Jahrhunderts gab es dann immer wieder solche Auswanderungswellen, $1846 / 47$ in der großen Hungersnot nach der Kartoffelmißernte waren es allein 100000. Der Gipfel der deutschen Auswanderung wurde nach dem Scheitern der Revolution 1854 wiederum während einer Krise mit 230000 Menschen erreicht, um dann nach Ausbruch des Sezessionskrieges auf 30000 jährlich zurückzugehen. Die großen Einschiffungshäfen waren zunächst Le Havre und Antwerpen, dann Bremen und zuletzt Hamburg. Die Hamburger Kauf- 
$655 \mathrm{~km}$ Elbestrecke im 19. Jh. durch Regulierung befahrbar wurden, bekam die Hansestadt gleichsam ein riesiges Hinterland. So verband bei Lauenburg der Elbe-TraveKanal die Nordsee mit der Ostsee und die Havel die Elbe mit der Oder. Berlin $(370 \mathrm{~km})$, Dresden $(570 \mathrm{~km})$, Breslau $(810 \mathrm{~km})$, Posen $(740 \mathrm{~km})$, Danzig $(994 \mathrm{~km})$ und Gleiwitz I0I0 $\mathrm{km}$ ) waren von Hamburg aus auf dem Wasserweg erreichbar geworden. Ähnlich schnell entwickelte sich seit der Mitte des 19. Jh. die Eisenbahn als zusätzliches Transportmittel. Die im Seeschiff ankommende Gütermenge stieg zwischen I8 56 und 1886 um 305 v. H., die im Flußschiff um 404 v. H. und die mit der Eisenbahn um 9I 3 v. H. ${ }^{29}$. Das I9. Jh. brachte aber auch eine völlige Revolutionierung der Seeschiffahrt: Noch zu Beginn des Jahrhunderts wies die Schiffahrt im Grunde dieselbe Form auf, wie sie sich am Ausgang des Mittelalters herausgebildet hatte. Wo die Größe des Schiffes eine rein handwerksmäßige Organisation ausschloß, wurde die Reederei im Anschluß an den Handel als kaufmännisches Nebengewerbe oder aber als Partenreederei betrieben. Nach den Erinnerungen des berühmten Hamburger Reeders Sloman gab es in den dreißiger Jahren mit Ausnahmen noch keine eigentlich selbständige Reederei in Hamburg. Innerhalb weniger Jahre wurde die Schiffsreederei nun zu einer selbständigen, rein kapitalistischen Organisation ausgebaut ${ }^{30}$. I 839 rief Robert Miles Sloman zu einer ersten Aktienreederei auf und konnte I84I schon mit der "Hanseatischen Dampfschiffahrtsgesellschaft « mit zwei Raddampfern den Betrieb aufnehmen ${ }^{31}$. Am Schluß des Jhs. gab es I I 5 deutsche Reedereien für eiserne Segelschiffe und 256 Dampfschiffahrtsreedereien, von denen 29 Aktiengesellschaften allein mehr als eine halbe Milliarde Mark in der Schiffahrt angelegt hatten. Ein Ausdruck dieser ungeheuren Expansion war die Vermehrung des Schiffsbestandes und der Größe der Schiffsgefäße: I 850 betrug der Nettoraumgehalt der deutschen Handelsflotte rund 0,5 Mill., I870 I Mill., I 9002 Mill. und I 9 I 23 Mill. Nettoregistertonnen. Entsprechend wuchs die Größe: Nach einer Hamburger Statistik hatte im Durchschnitt der Jahre I84I-45 ein Schiff ein Raumgehalt von I $87 \mathrm{BRT}$, I $871-75469 \mathrm{BRT}$, I 896-I900 II $20 \mathrm{BRT}$ und I906-I9 I0 I 26 I BRT ${ }^{32}$. Dabei darf die Rolle des Dampfschiffes zunächst nicht sehr hoch bewertet werden. Zwar

mannschaft hat zunächst den Auswanderertransport als nicht ganz standesgemäßes Gewerbe betrachtet, ihre Hauptinteressen lagen allerdings auch nicht in Nordamerika. Eine erste Förderung des Auswandererverkehrs in Hamburg durch den Senat ist seit $1836 \mathrm{zu}$ beobachten. Als das früher bestehende Auswanderungsverbot in Hamburg aufgehoben wurde, empfand man eine weitere Senatsverordnung über die Art der Verschiffung von Zwischendeckspassagieren als so hinderlich, daß man nach Hamburg kommende Auswanderertrupps lieber an befreundete englische Reeder weiterschickte. Infolgedessen ist Hamburg lange Zeit zunächst hinter der Bremer Auswandererquote zurückgeblieben. Alle Zahlen und Einzelheiten bei Hermann Oncken, Die deutsche Auswanderung nach Amerika und das Deutsch-Amerikanertum vom 17. Jahrhundert bis zur Gegenwart, in: Historischpolitische Aufsätze und Reden Bd. I, München-Berlin I914, S. 97 ff. - Hermann Wätjen, Aus der Frühzeit des Nordatlantikverkehrs, Leipzig 1932. - Ernst Baasch, Gesetzgebung und Einrichtungen im Interesse des Auswanderungswesens in Hamburg, in: Auswanderung und Auswanderungspolitik in Deutschland, hrsg. von Eugen von Philippovich, Leipzig 1892, S. 389 ff.

${ }^{29}$ Wendemuth-Böttcher, Hafen von Hamburg a.a.O. S. 228.

30 Werner Sombart, Die deutsche Volkswirtschaft im I9. Jahrhundert und im Anfang des 20. Jahrhunderts. 7. Aufl. Berlin 1927 S. 262 ff. - Fitger, Seeschiffahrt a. a. O. S. 28.

31 O. Matbies, Hamburgs Reederei $1814-1914$, a. a. O. S. 76.

${ }^{32}$ Sombart, Deutsche Volkswirtschaft im I9. Jahrhundert a. a. O. S. 267. 
wat das erste englische Dampfschiff "The Lady of the Lake« schon I 816 vor Hamburg erschienen, und bald darauf gab es einen Dampffährverkehr mit Harburg, aber das Segelschiff blieb aus Rentabilitätsgründen noch bis ins späte I9. Jh. hinein dominierend. Die ersten Dampfer waren sehr reparaturanfällig und verbrauchten sehr viel Kohlen. Erst die Einführung der Mitteldruck- und Dreifach-Expansionsmaschine nach I860 senkte den Kohlenverbrauch entscheidend und brachte den Durchbruch der Dampfschiffahrt auch in der Frachtenfahrt ${ }^{33}$. Tonnagemäßig überflügelten die Dampfer allerdings schon ab $\mathrm{I}_{863}$ die Segler in Hamburg ${ }^{34}$. Schneller setzte sich der Eisenrumpf durch; bis 1870 verschwand das hölzerne Segelschiff fast völlig ${ }^{34}$. So müssen wir uns das Bild des Hamburger Hafens beim Beginn der Modernisierung vor roo Jahren noch als einen Wald voller Segelmasten vorstellen. Bilder im Museum für hamburgische Geschichte belegen dies auch ganz deutlich.

Durch das sich geradezu überstürzende Ansteigen der ein- und auslaufenden Schiffe wie auch durch das Anwachsen der Schiffsgrößen ergab sich von selbst die Notwendigkeit, den Hafenumschlag entscheidend zu verbessern. Zuvor war es selbstverständlich gewesen, daß die Besatzung alle Lösch- und Ladearbeiten selbst besorgte. Die Besatzungen von Segelschiffen waren im Vergleich zu denen von Dampfschiffen recht zahlreich und die Ladefähigkeit relativ gering. Auch war der Gewinn bei früheren Schiffsreisen, die ein ganz anderes Risiko wie heute einschlossen, so groß, daß der Zeitfaktor eine ziemlich untergeordnete Rolle spielte ${ }^{35}$. Oft suchte sich der Kapitän in fremden Häfen die Ladung für die Rückfracht selbst zusammen, was wochen- oder sogar monatelang dauerte. Als sich die Schiffe im Rahmen der Aktiengesellschaften zu teuren Investitionen entwickelten, mußte der schnelle Umschlag zum Haupterfordernis werden. Verkleinerte Mannschaften, Steigerung der Ladekapazität und Reduzierung der Liegezeiten wurden nun zum Charakteristikum des rational und nach kapitalistischen Prinzipien durchgeführten Seetransports. Laden und Löschen wurde nun von ortsansässigen Hafenarbeitern übernommen ${ }^{36}$.

\section{Ausbau und Modernisierung des Hafens}

Die erwähnten kleinen Hafenverbesserungen und Elberegulierungen dürfen nicht darüber hinwegtäuschen, daß sich der Hamburger Hafen seit dem großen Festungsbau zwischen I616 und I625 bis zur Mitte des 19. Jhs. im Grunde kaum veränderte. Noch immer ankerten in den vierziger und fünfziger Jahren die größeren Seeschiffe mitten

${ }^{3}$ Teutebcrg, Industrialisierung der britischen Seeschiffahrt a. a. O. S. 260.

${ }^{34}{ }_{1863}$ überstieg die Tonnage der im Hamburger Hafen liegenden Dampfschiffe um 519000 BRT erstmals die der Segelschiffe (46r 000 BRT). Die Anzahl der Segelschiffe mit 3353 Einheiten war aber noch fast zweimal so groß wie die der Dampfschiffe ( 379 Einheiten). Noch beim Zollanschluß Hamburgs I 888 war Deutschlands Segelflotte etwa fünfmal größer als die Dampferflotte. Der Sieg des Dampfschiffes in der Seeschiffahrt darf also nicht zu früh angesetzt werden. Die technische Erfindung und ihr ökonomischer Durchbruch sind nicht identisch. Der Ausbau des Hamburger Hafens fällt gerade in die entscheidende Umbruchperiode vom Segel- zum Dampfschiff auf dem Weltmeer. Vergl. Sombart ebd. Böer-Lebe, 750 Jahre Hamburger Hafen S. so.

${ }^{35}$ Fitger, Seeschiffahrt a. a. O. S. 37.

${ }^{38}$ Klugmann, Hamburger Hafenarbeiter a. a. O. S. I3. 
auf dem Strom an den Dückdalben, von wo die Ladung mit Hilfe von Flaschenzügen an der Takelage auf Schuten und Jollen gelöscht und rudernd bzw. stakend auf den Fleeten zu den Speichern der Innenstadt gebracht wurde. Der Liegeplatz auf der Elbe hieß der äußere Niederhafen und zerfiel in drei Teile: den schon erwähnten älteren Rummelhafen beim Niederbaum, den Jonas-Hafen bei den heutigen St.-Pauli-Landungsbrücken und den sog. Brandenburger Hafen beim »hölzernen Wambs« (Blockhaus). Der offene Stromhafen mit seinen Dückdalbenreihen längs des Nordufers war etwa $1000 \mathrm{~m}$ lang und $140 \mathrm{~m}$ breit und bedeckte etwa I,4 ha. Er gewährte damit I 30 größeren und ebensoviel kleineren Schiffen Raum zum Liegen, Laden und Löschen ${ }^{37}$. Die kleineren Schiffe ankerten gewöhnlich wie noch im Mittelalter in der vor der Alstermündung gelegenen kleinen Bucht hinter dem Johannisbollwerk, dem Binnen- oder inneren Niederhafen. Dieser besaß eine Länge von $710 \mathrm{~m}$, eine mittlere Breite von $15 \circ \mathrm{m}$ und einen Flächenraum von r,6 ha. Darin lagen wie auf den Fleeten gewöhnlich 250 kleinere Schiffe sowie allerhand Kähne und Ewer. Ein an der östlichen Spitze des groBen Grasbrooks elbaufwärts nach Norden abzweigender Flußarm bildete den »Oberhafen«, wo die Elbkähne oder kurz »Oberländer«, nachdem sie die Akzisegrenze am »Oberbaum« passiert hatten, ihren Liegeplatz fanden. Er hatte eine Länge von $1300 \mathrm{~m}$,

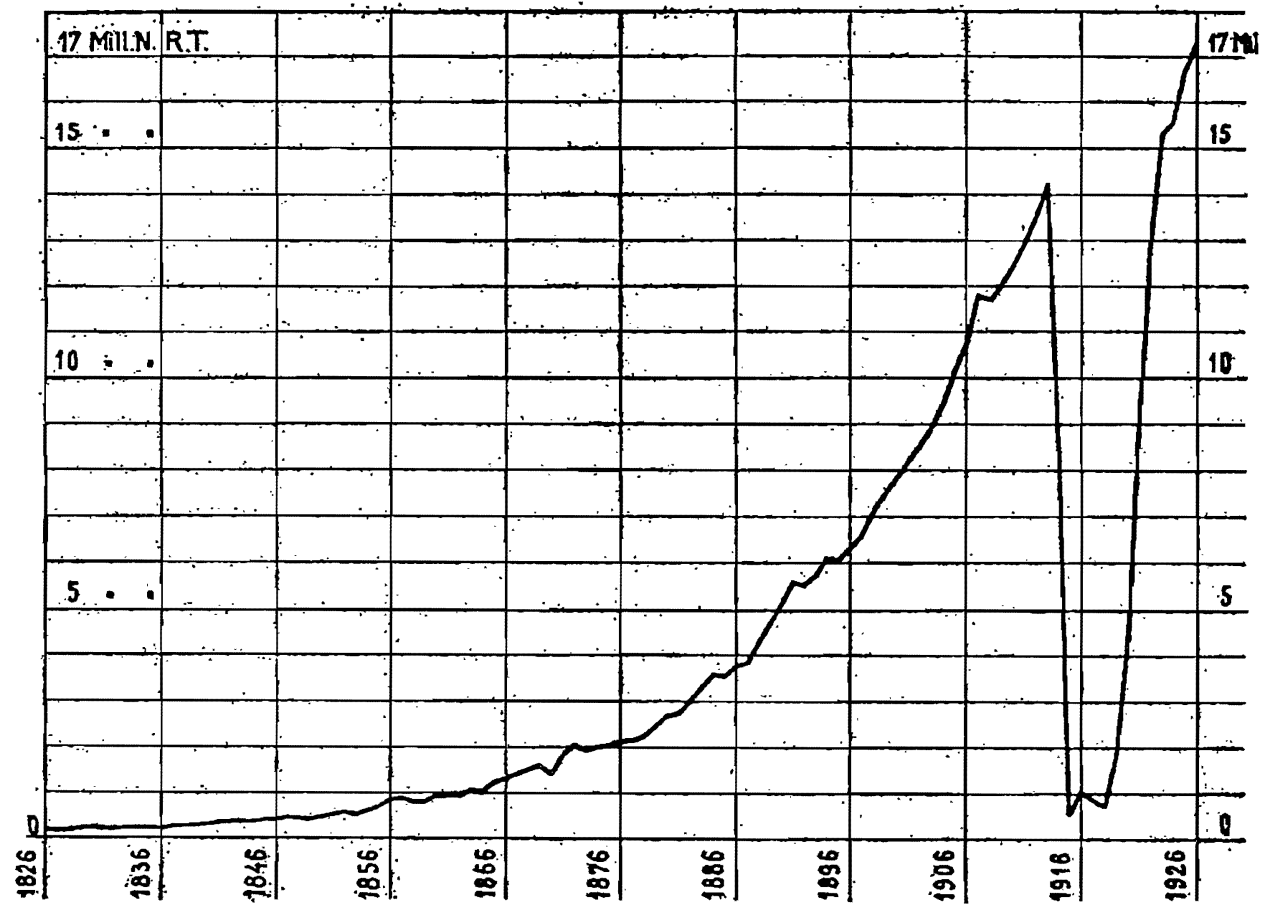

Schaubild r: Die Entwicklung des Seeschiffsverkehrs in Hamburg zwischen 1826 und $1926{ }^{38}$

${ }^{37}$ Eine gute Anschauung des Hamburger Hafens aus dem Jahre I 836 vermittelt ein Panoramabild in Böer-Lebe, 750 Jahre Hamburger Hafen S. 42/43. Vergl. ferner MacElwee, Hamburger Hafenbaupolitik a. a. O. S. Is (Fußnote I). - C. F. Gaedecbens, Historische Topographie der Freien und Hansestadt Hamburg von der Entstehung bis auf die Gegenwart, Hamburg 1880, S. I69.

${ }^{38}$ Die Statistik wurde entnommen aus Wendemuth-Böttcher, Hafen von Hamburg a. a. O. S. 28. 


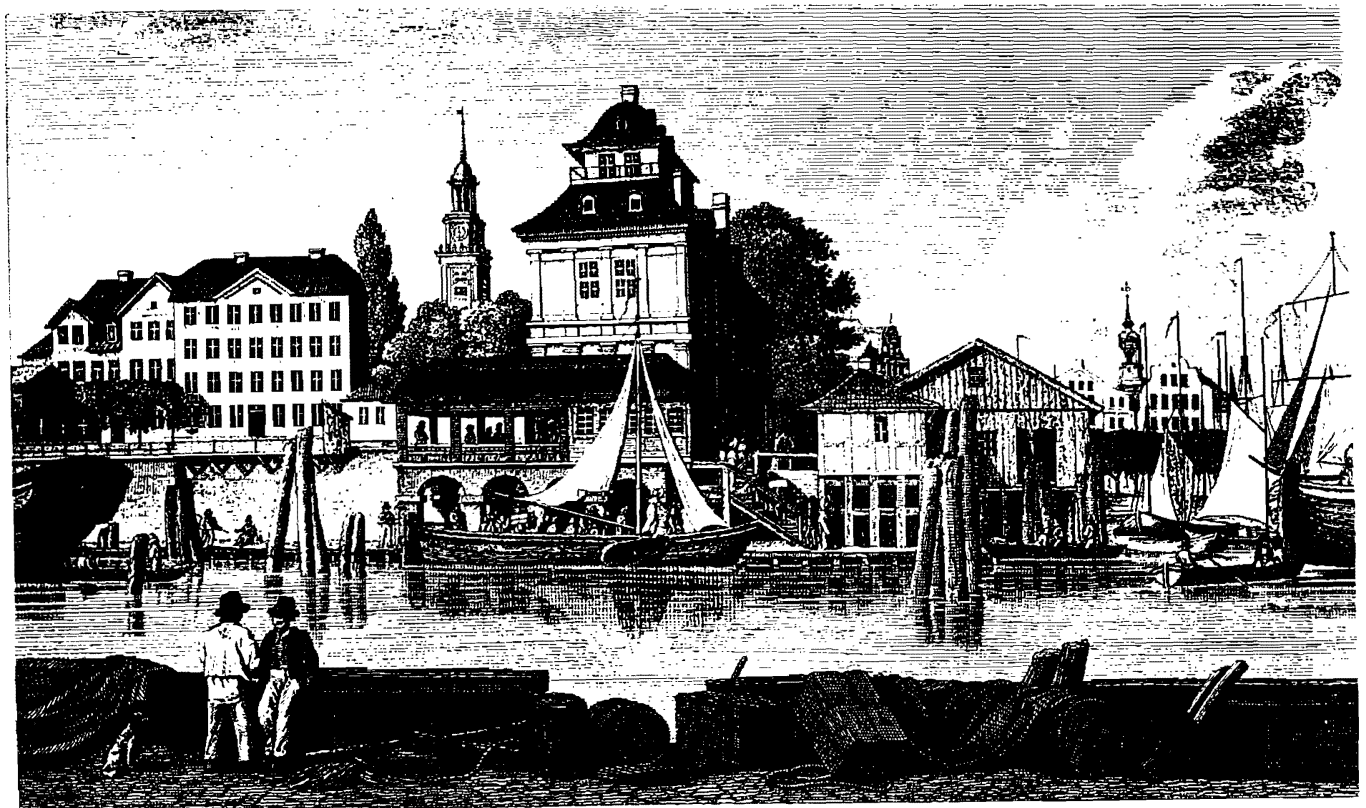

Das alte Baumbaus in Hamburg

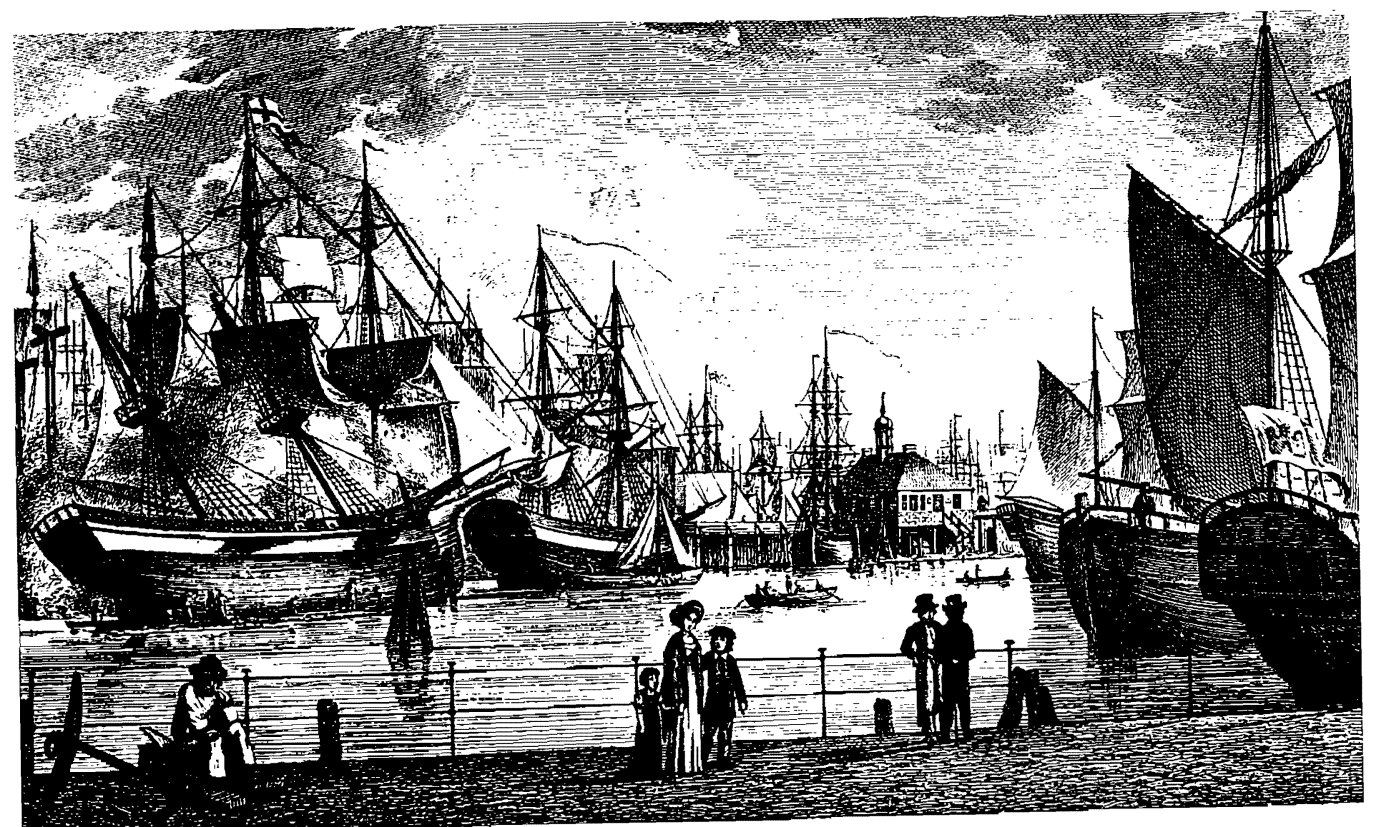

Der Hafen beim Blockbanse in Hamburg (erbant 1655) 


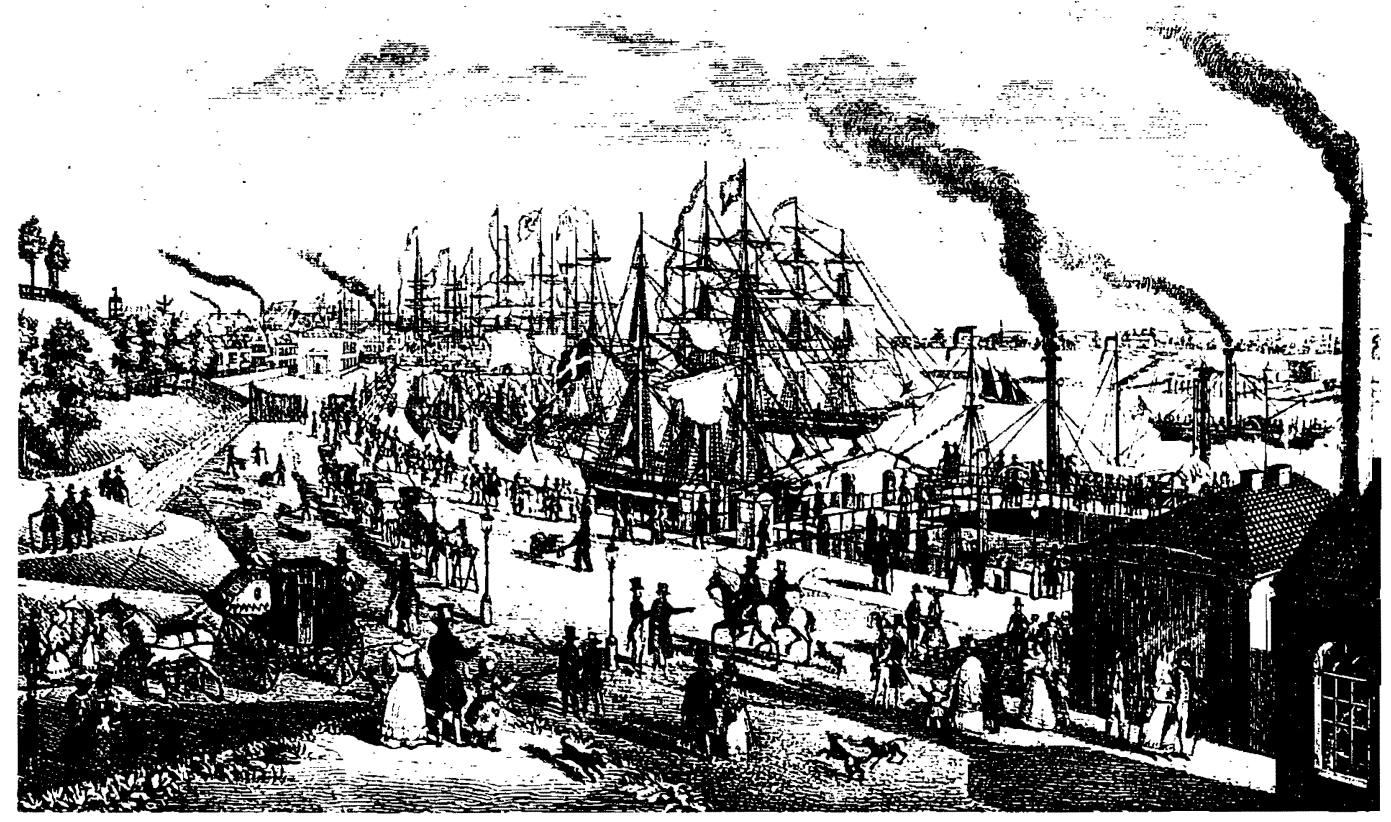

Der nene Hafen $\mathrm{um}$ I 850

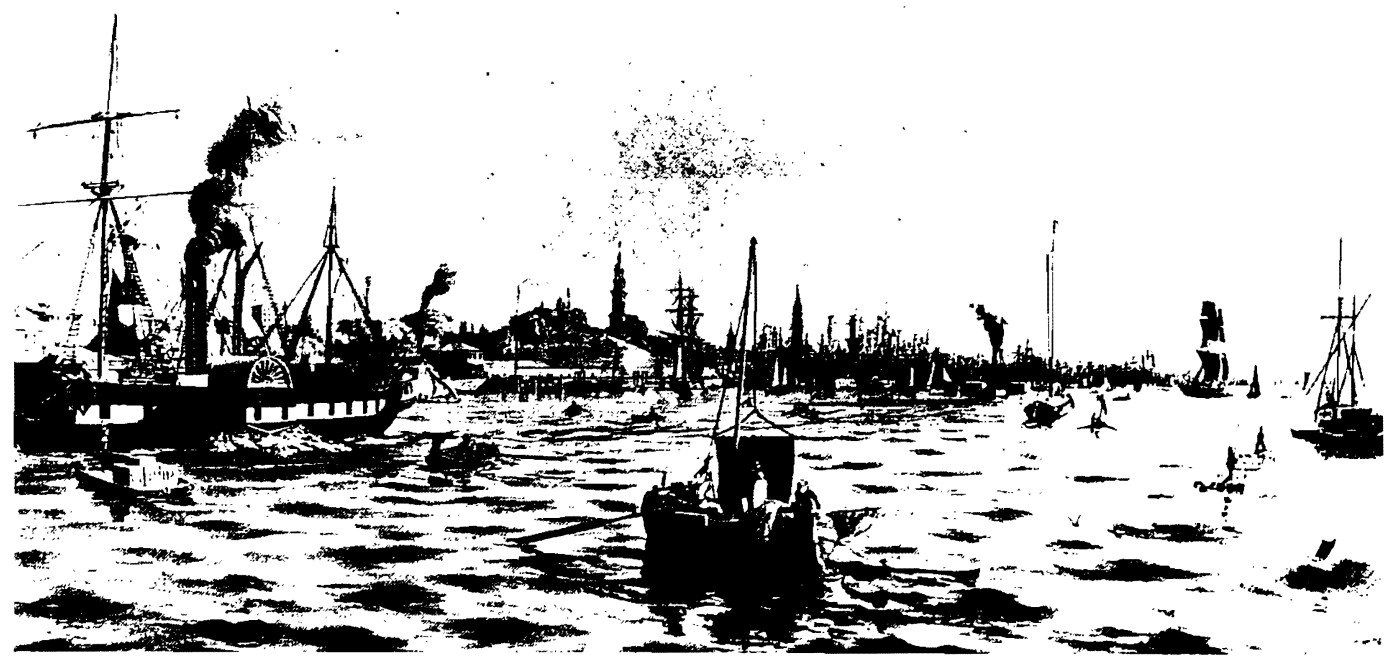

Hafenpanorama $\mathrm{Hm}$ I 850 
eine mittlere Breite von $70 \mathrm{~m}$ und einen Flächenraum von 0,9 ha, faßte insgesamt etwa 260 Elbkähne und zum Zwischenverkehr gehörende Fahrzeuge. Insgesamt bedeckte also der alte Hamburger Hafen um die Mitte des vorigen Jahrhunderts nur 3,9 ha. Mit dieser heute geradezu winzig vorkommenden Hafenfläche war man jahrhundertelang gut ausgekommen. Schaut man sich die Entwicklung des Seeverkehrs in der Statistik an, so konnte vor 1836 auch kaum ein Bedürfnis nach Erweiterung vorhanden gewesen sein.

Wie bescheiden der Hamburger Hafen zu Beginn des vorigen Jahrhunderts noch gewesen ist, ergibt sich aus einem Vergleich mit englischen Häfen und speziell mit den Investitionen für den Londoner Hafen. Dort wurden im Rahmen eines steigenden Schiffsverkehrs schon 1705 1 335 Schiffe mit I 57000 dwt, I 794 aber 3663 Schiffe mit 620000 dwt allein von ausländischen Häfen kommend gezählt. Um I 800 frequentierten nach verläßlichen Zählungen jährlich über 8000 See- und Küstenschiffe den Londoner Themsehafen. Zwischen 1694 und 1700 entstand das erste künstliche Hafenbecken, "The Howland Great Wet Dock«, das durch eine Schleuse abgeschlossen wurde. I 802 wurde das berühmte »West India Dock« mit je zwei Becken von $780 \mathrm{~m}$ Länge und $\mathrm{I} 20$ bzw. I $50 \mathrm{~m}$ Breite eingeweiht. Ein Becken war also so groß wie der ganze Hamburger innere Niederhafen. Danach entstanden in der Zeit des Dock-Booms das fast ebenso große »London Dock" I805 und die »East India Docks". Zwischen I800 und I 805 investierte man allein in London 5,4 Mill. Pfd. St., bis 1864 sogar I6 Mill. Pfd. St. ${ }^{39}$. Hamburg tat dagegen lange über die Franzosenzeit hinaus so gut wie gar nichts ${ }^{40}$. Zwar wurde 1814 als erstes Zeichen einer neuen Initiative eine "Schiffahrts- und HafenDeputation « an Stelle der früheren Admiralität und der Elbe-Deputation als Vorläuferin der heutigen Abt. Strom- und Hafenbau bei der Baubehörde gebildet, doch geschah in Wirklichkeit nicht sehr viel. Erst der in den dreißiger und vierziger Jahren anwachsende Schiffsverkeht machte die Hafenerweiterung dann vordringlich. I 837 nannte die Statistik 2600 einlaufende Schiffe mit zusammen 262000 BRT. Ein Jahr zuvor hatte wie erwähnt der große Auswandererverkehr begonnen ${ }^{41}$. Drei Probleme waren es, die auf Hamburg nun zukamen:

I. Ausbau und Vertiefung der Elbe.

2. Schaffung größerer Hafenbecken.

3. Entwicklung neuer Umschlagtechniken und Förderung der Infrastruktur.

Alle drei Fragen waren durch gleiche Ursachen bedingt und eng miteinander verbunden; alle Hafenprojekte nahmen darauf Bezug. Zur besseren Übersicht sollen sie aber hier getrennt behandelt werden.

39 Teuteberg, Industrialisierung der britischen Seeschiffahrt a. a. O., S. 234.

${ }^{40}$ Zwischen 1859 und 1868 sind 21,4 Mill. Mark für Strom- und Hafenbau in Hamburg aufgewandt worden. Dieser Betrag fällt aber bereits mit der ersten Ausbauphase zusammen.

41 Von den 1837 in Hamburg einlaufenden Schiffen segelten aber 883 unter englischer, 438 unter hannoverscher, 409 unter dänischer und nur 319 unter Hamburger Flagge, der Rest kam aus noch anderen Staaten. Altona hatte zu dieser Zeit nur noch 5 I Schiffe, war also gegenüber dem Stand um I 800 stark zurückgefallen. Dagegen hatte sich im frühen 19. Jahrhundert die Blankeneser Schiffahrt stark aufwärtsentwickelt. Dort waren 247 Schiffe beheimatet, meist allerdings nur kleine Fischboote. 


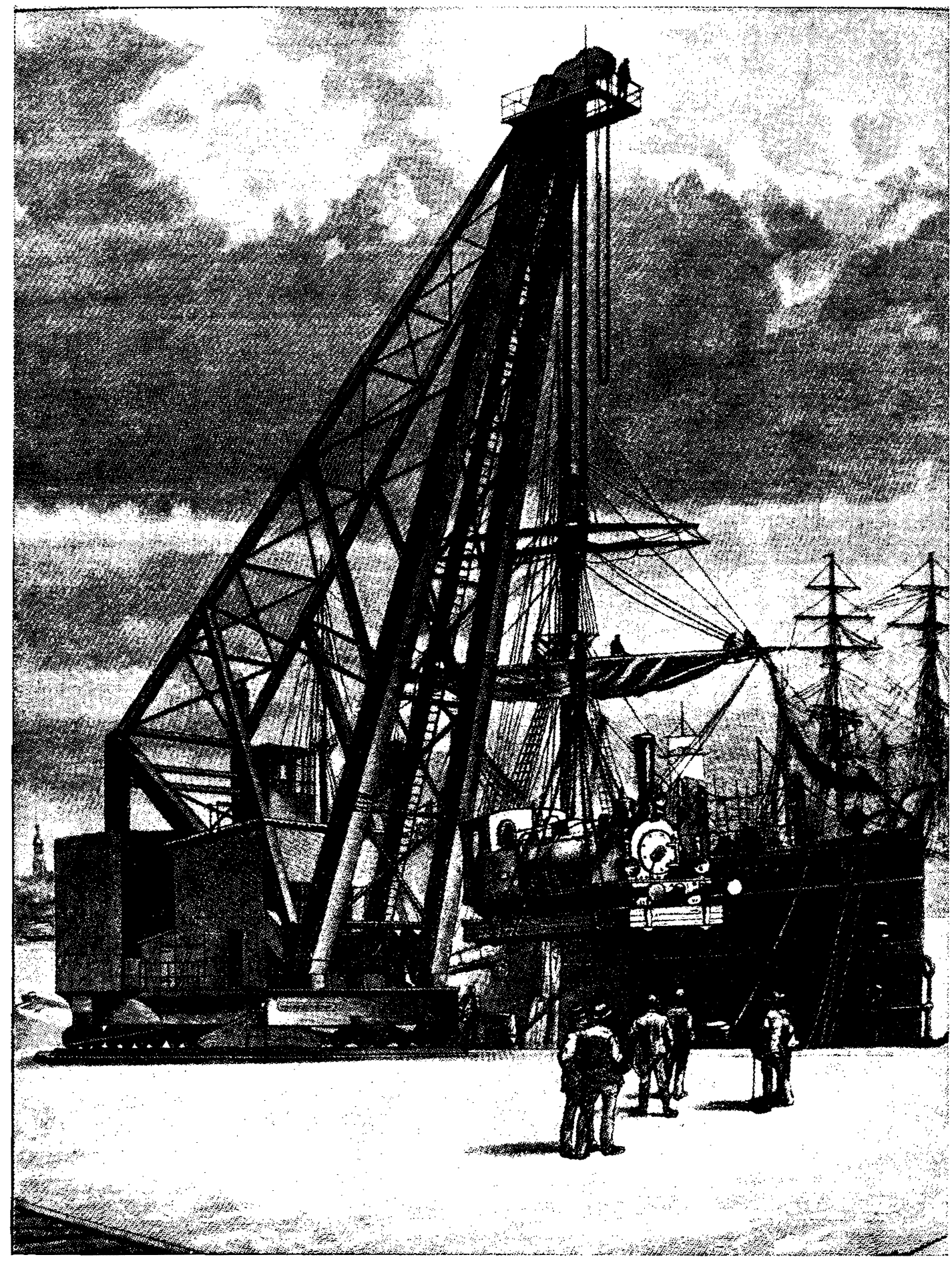

Einer der ersten Dampfkräne am Asiakai um I 888 
a) Regulierung und Vertiefung der Elbe

Die Korrektion und Vertiefung der Elbe war wie erwähnt ein jahrhundertealtes Problem, weil diese gerade im Unterlauf bis zur Mündung ein ungleichmäßiges Bild bietet. So verbreitert sich unterhalb von Finkenwärder der $600 \mathrm{~m}$ breite Fluß auf $2800 \mathrm{~m}$, um bei Brunshausen wieder I $200 \mathrm{~m}$ zu erreichen. Diese ungleichmäßige Breite führte immer wieder zu Bildung vieler Nebenwasserarme, was die natürliche Spülkraft des Stromes schwächte. Es bildeten sich immer wieder Sandbänke (Barren), die besonders zwischen Blankenese und Schulau größte Unannehmlichkeiten bereiteten. Bis zur Mitte des 19. Jhs. schafften es größere Schiffe oftmals nicht einmal bei Flut, diese natürlichen Barrieren zu nehmen und mußten vorher einen Teil der Ladung leichtern, um nach Hamburg zu kommen. Schon frühzeitig versuchte man daher nach holländischem Vorbild, mit Handbaggern und Drehewern die Fahrrinne zu vertiefen. Aber die geförderten Mengen waren zu gering, auch erschwerte der alte Handelsrivale Dänemark als Anliegerstaat solche Arbeiten ${ }^{42}$. Der aus dem hamburgischen Amt Ritzebüttel kommende Wasserbaudirektor Reinbard Woltmann, der schon 1784 im Auftrag des Rates das englische Fluß- und Kanalwesen auf einer Reise studiert hatte, schuf nicht nur die ersten Grundlagen der Elbuferbefestigung, sondern ließ auch I 834 den ersten Dampfbagger anschaffen ${ }^{\mathbf{4}}$. Ein zweiter Dampfbagger mit doppelter Leistung und Greiftiefe kam I 838 hinzu. Ab 1846 wurden beide erstmals auch auf der Unterelbe zur Begradigung der gekrümmten Fahrrinne eingesetzt. Wie die Zahlen über die geförderten Erdmengen zeigen, überflügelte die mechanische Naßbaggerei schnell die herkömmliche Handbaggerei ${ }^{44}$. Aber durch die Baggerei war das Problem nicht allein zu lösen, da es immer 42 Vergl. Walter Springe, Historische Baggermaschinen, Berlin 1938, S. 57. Carl Friedrich Wiebeking, Praktischer Wasserbau und Maschinenlehre, Düsseldorf 1792. - Heinricb Hïbbe, Das Fahrwasser der Elbe, 2. Aufl. Hamburg 1848. - Reinbard Woltmann, Kurzgefaßte Geschichte und Beschreibung der Wasserbauwerke im Amte Ritzebüttel, Hamburg 1807. - W. Conradis, Geschichte der Naßbaggerei, Diss. Berlin 1938.

43 Der aus der Nähe Bremens stammende Bauernsohn Reinhard Woltmann (1757-1837) war erst Dorflehrer, dann Schreiber und Unteraufseher im hamburgischen Amt Ritzebüttel gewesen. Dabei bewährte er sich so sehr in der Anlage von Uferbestigungen und der Einrichtung von Seezeichen, daß der Hamburger Senat ihm eine Ausbildung auf der Büsch'schen Handelsakademie in Hamburg und der Universität Kiel finanzierte. Als "BauConducteur« von Ritzebüttel machte dann Woltmann eine große technologische Bildungsreise. Die im Ausland gewonnenen Erfahrungen setzten ihn dann in Stand, eine erste mustergültige Elbuferbefestigung zu schaffen. Der Ausbau des Cuxhavener Hafens, die Befestigung der Insel Neuwerk mit ihrem Leuchtturm, der Erlaß von wichtigen Deichordnungen und anderes mehr geht auf das Konto dieses führenden Wasserbautechnikers, der mit seinen zahlreichen Schriften auch außerhalb Hamburgs zu großem Ansehen kam. Seine Abhandlungen dienten ganz Deutschland als Vorbild, was in der Verleihung der Mitgliedschaft vieler wissenschaftlicher Gesellschaften zum Ausdruck kam. Vergl. Reinbard Woltmann, Beyträge zur Hydraulischen Architectur Bd. 4: Hydraulisch-architectonische Reisebemerkungen. Göttingen 1799. - Ders., Beyträge zur Baukunst schiffbarer Kanäle, Göttingen 1802. - Ders., Geschichte und Beschreibung der Wasserwerke im Amte Ritzebüttel, Hamburg 1807. Hermann Joachim, Art. R. Woltmann in: Allgemeine deutsche Biographie Bd. 24 (1898), S. I92-199. - Becker, Cuxhaven a. a. O. - Kolalewski, Geschichte der Hamburgischen Gesellschaft zur Beförderung der Künste und nützlichen Gewerbe, Hamburg I 897.

44 Wie sehr die Baggerei auf der Elbe innerhalb kurzer Zeit zunahm und die alte Handarbeit durch Maschinen verdrängt wurde, geht aus folgenden Zahlen hervor: Um I834 gab es erst zwei Drehewer von je 600 Kubikfuß Fassungsvermögen und eine kleine Anzahl von Handbaggerschuten. 1847 konnten dagegen schon 6 Drehewer von je 800 Kubikfuß, ein kleiner und zwei große Dampfbagget sowie eine Tauchglocke eingesetzt werden. x 85 I förderten die Dampfbagger bereits dreimal und I 856 fünfmal soviel Erdmengen wie Drehewer und Handbagger 
neue Sände gab. Noch 1847 beklagte eine Schrift den ungenügenden Zustand des Fahrwassers ${ }^{45}$.

Gleichzeitig wurden daher Stromregulierungen vorgenommen, um die Spülkraft besser auszunutzen. Besonders nachteilig war es, daß sich die Elbe in einen nördlichen und südlichen Arm teilte, die sich erst an der Bunthäuser Spitze vereinigten. Zeitweise war die Norderelbe so versandet, daß die oberländischen Elbkähne den Umweg über die Süderelbe nach Hamburg machten. Die Süderelbe war wesentlich kürzer als die Norderelbe. Demzufolge traf die Flutwelle der Süderelbe früher bei der Bunthäuser Spitze ein und floß dann in die Norderelbe, wo sich das Wasser staute und Sinkstoffe ablagerte. Wasserbaudirektor Woltmann und sein Nachfolger Heinrich Hïbbe, die ohne Übertreibung nach ihren Büchern zu urteilen zu den größten Wasserbaufachleuten ihrer Zeit gerechnet werden können, arbeiteten erstmals umfassende Korrektionspläne aus und errichteten Hunderte von Stackwerken. Entscheidende Verbesserungen bei der Versandung der Norderelbe konnten aber erst erreicht werden, als Hannover i 866 preuBisch wurde und nun gemeinsam mit Hamburg daranging, die Stromverhältnisse zu regulieren. 1868 wurde der erste Vertrag zur Vertiefung des Köhlbrands und der beiden Stromarme geschlossen. Dieser erste Köblbrandvertrag ist ein Markstein in der Geschichte des Hamburger Hafens, denn nun wurde die Elbe-Schiffahrt entscheidend verbessert. Verbreiterung der Fahrrinne an den engen Stellen, Festlegung von Uferlinien, Anlage von Leitdämmen für die Zusammenfassung des Hochwassers und Verkürzung der Krümmungen der Norderelbe waren die Folge. Die Landspitze am Bunten Hause wurde so verlängert, daß die Flutwellen fast gleichzeitig dort eintrafen und die gleichmäßige Durchspülung der Norderelbe gesichert war. Auch half hier noch ein Durchstich bei der Insel Kaltehof ${ }^{46}$. Während früher Schiffe von mehr als $4,3 \mathrm{~m}$ Tiefgang bei mittlerem Hochwasser schon bei Blankenese ankern mußten, konnten nun die Tauchtiefen 1859 auf $5,3 \mathrm{~m}, \mathrm{I} 869$ auf $5,9 \mathrm{~m}, 1879$ auf $6,7 \mathrm{~m}$ und $\mathrm{I} 889$ auf $7,2 \mathrm{~m}$ gebracht werden. Im 2. Köhlbrandvertrag von I 896 vereinbarten die drei Städte Hamburg, Altona und Harburg eine weitere Vertiefung des Köhlbrands, Bau eines geschützten Altonaer Hafens und Regulierung der Norderelbe zwischen Altona und Nienstedten. Der 3. Köhlbrandvertrag I 9 ro vertiefte die Elbe auf io $\mathrm{m}$, womit fast schon die heutige Tauchtiefe erreicht ist. Auch der Einsatz von Dampfeisbrechern ab I874 machte die Schiffahrt auf der Elbe intensiver und regelmäßiger. Lag zwischen I 8 I 6 und 1820 die Schiffahrt durchschnittlich an 56 Tagen im Jahr (I5,3 V. H.), I 82 I und I 825 an 43 Tagen (I I, 8 v. H.), I 826 und I 830 an 72 Tagen ( 19,7 V. H.) still, so war die Schiffahrt ab i 876 endgültig das

zusammen. Später stiegen die gebaggerten Mengen noch mehr an. Wurden 1857 nämlich erst zusammen I Mill. cbm gehoben, so stieg diese Menge 1903 auf 3,2 Mill. cbm und 1907 sogar auf 7 Mill. cbm. Vergl. MarElwee, Hamburgs Hafenbaupolitik a. a. O. S. 68, und Wendemutb-Böttcher, Hafen von Hamburg a. a. O. S. 208.

${ }_{45}$ In einem zeitgenössischen Artikel heißt es dazu: "Möge der ungenügende Zustand des Fahrwassers auf der Strecke von Neßhaken bis unterhalb Schulau von manchen übertrieben dargestellt werden, so herrscht doch darüber nur eine Stimme, daß die Untiefen, namentlich wegen der zunehmenden Dampfschiffahrt von Jahr zu Jahr lästiger werden, daß demnach die Herstellung eines unserem Handel entsprechenden Fahrwassers selbst mit bedeutenden Opfern zu erstreben sei.« Zitiert aus $P$. C. Schauman, Die von Hamburg ausgeführten Verbesserungen des Hafens, der Rhede und des Fahrwassers der Elbe, in: Neue Hamburgische Blätter Jg. 1847, S.22. ${ }^{46}$ Bucbheister, Die Elbe und der Hafen von Hamburg a. a. O. S. 20. 
ganze Jahr über eisfrei. Das alles wurde durch eine gewaltige Vermehrung der Kosten erreicht: I 868 brachte man für den ersten Regulierungsplan erst $525000 \mathrm{M}$ banco, 1908 in der dritten Stufe schon 40 Mill. M auf ${ }^{47}$.

\section{b) Hafenpläne und der Bau des Sandtorbafens}

Auch für das zweite große Problem, der Schaffung größerer und wesentlich leistungsfähigerer Hafenbecken, gab es seit dem großen Handelsaufschwung Ende des I 8. Jhs. schon Pläne. Um den alljährlichen Hochwasserkatastrophen, bei denen die niedrigen Hafenviertel überschwemmt wurden, zu begegnen, wollte Hamburgs berühmter Merkantilist Johann Georg Büsch schon 1786 die ganze Stadt eindeichen, wobei der innere Niederhafen und die Fleete vom äußeren Niederhafen auf der Elbe durch Schleusentore getrennt werden sollten ${ }^{48}$. Schon hier wurde die für den ganzen Hamburger Hafenbau so entscheidende Frage berührt: Soll Hamburg ein Dockhafen (Schleusenhafen) nach englischem Vorbild oder ein offener Tidehafen werden? Offenbar waren Büsch die Pläne auf einer kurz zuvor geführten Englandreise gekommen, wo er die weiter fortgeschrittene Wasserbautechnik studiert hatte. Als erster in Deutschland äußerte er nun den Gedanken an den Bau eines großen modernen Kunsthafens. Wegen der nachfolgenden Handelskrisis und des englisch-französischen Krieges mit Elbblockade und Kontinentalsperre blieb sein Plan ebenso unausgeführt wie der des Hamburger Stadtingenieurs Kapitän Baxmann aus dem Jahre 1796, der die sumpfigen Wiesen des Grasbrook zwischen der südlichen Stadtmauer und der Elbe mit einem Wall umgeben und in das Geschäfts- und Speicherviertel von St. Katharinen eindeichen wollte. Der starke Rückgang der Einwohnerschaft und des Handels ließ dann erst i 828 wieder den Hafenverbesserungsplan aufleben. In diesem Jahr machte Woltmann, seit I8 I4 an der Spitze der neugeschaffenen Schiffahrts- und Hafendeputation stehend, erneut den Vorschlag, den Grasbrook einzudeichen, mit Kanälen zu versehen und dann mit Schleusen dem Hafen anzuschließen. Im Grunde war dies nur eine verbesserte Auflage des alten Büsch-Planes von 1786 , dem es mehr um die Sicherung und Erweiterung des Stadtgebietes als den eigentlichen Hafenausbau gegangen war. Wie aus den gedruckten »Rats- und Bürgerbeschlüssen « erkennbar ist, entstand zwischen I 835 und I 845 die eigentliche Wende hin zum großzügigen Hafenausbau ${ }^{49}$. Wasserbaudirektor Heinrich Hiibbe wurde zu einer Studienreise wiederum nach England gesand $t^{50}$ und der "rühmlichst bekannte« eng-

47 MacElwee, Hamburgs Hafenbaupolitik a. a. O. S. 63 und S. 104. Vergl. H. Blobm, Die Fahrbahn der Elbe und ihre Verbesserung, Hamburg 1841. - v. Bose, Beschreibung der Elbe mit ihren Zuflüssen, Annaberg 1852. J. Dalmann, Stromcorrectionen im Fluthgebiet, Hamburg I 856. - M. Görz und M. Bucbbeister, Das Eisbrechwesen im Deutschen Reich, Berlin I 900.

48 Johann Georg Büsch, UUbersicht des gesamten Wasserbaus, 2 Theile, Hamburg 1796.

${ }_{49}$ Vergl. Peter David Lobmann (Hrsg.), Rats- und Bürgerbeschlüsse Bd. 4: 1836-1840, Hamburg I 840.

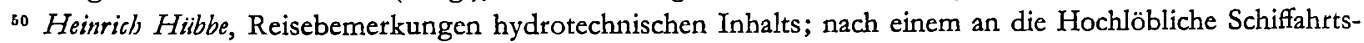
und Hafen-Deputation in Hamburg erstatteten Berichte, über die Mittel zur Vertiefung der Ströme im Fluthgebiete, und insbesondere über die auf einer Reise im Mai und Juni I 844 an den Flüssen Großbritanniens gesammelten Erfahrungen und Beobachtungen. Nebst einigen Folgerungen für die Untiefen der Elbe bei Blankenese und Schulau und drei Abhandlungen verwandten Inhalts, Hamburg 1844. - Hübbe informierte sich auf dieser Reise zwar in erster Linie über neue englische "Kratzmaschinen» (Dredging machines) zur Beseitigung 
lische Ingenieur Charles Vignoles, der mit seinen kühnen Versuchen einer »atmosphärischen Eisenbahn" in ganz Europa Aufsehen erregt hatte, zur Beratung nach Hamburg gerufen ${ }^{51}$. Letzterer wußte allerdings auch nichts Besseres, als aus dem Grasbrook ein System verschachtelter kleiner Hafenbecken mit Schleusenabtrennung von der Elbe zu machen. Ganz neu war sein Gedanke, eine Umschlagtechnik Seeschiff-Eisenbahn einzuführen. Er wollte den Grasbrook zum Eisenbahnhof ausbauen und mit der geplanten hamburgisch-hannoverschen Eisenbahnlinie in Verbindung bringen. Aber das Projekt scheiterte an der feindseligen Haltung Hannovers. Der Ausbau der ersten Strecke Hamburg-Bergedorf als Vorstufe der Strecke Hamburg-Berlin I 840 hatte nichts mit dem Hafenausbau zu tun.

Praktisch begann der erste reale Schritt zum Hafenausbau, als am 26. Oktober 1837 der Rat an die Erbgesessene Bürgerschaft den Antrag richtete, die alte Bastion Johannisbollwerk aus dem 30 jährigen Krieg abzutragen und davor eine erste Kaimauer für die Dampfschiffe im Jonashafen einzurichten ${ }^{52}$. Dies wurde auch bis 1843 durchgeführt. Es handelte sich aber noch nicht um einen modernen Anlegekai, sondern nur um eine einfache Spundwand in Holzbauweise. Dennoch war eine solche massive Einfassung etwas völlig Neues. Entsprechend hoch waren die Kosten, weil viele alte Pfähle gezogen, große Steine bewegt und der Kai wegen der Sturmfluten nachträglich erhöht werden mußte. ${ }^{53}$ Mit diesem Bau wurden die Hamburger erstmals mit der Tatsache konfrontiert, größere Summen für den Hafenbau bereitstellen zu müssen. Entsprechend groß waren anfangs die Widerstände in der Bürgerschaft und die Verzögerung bei der Bewilligung. Ausschlaggebend für die Bewilligung war schließlich die Furcht, der neue Dampferverkehr könne ohne den festen Weg auf dem Kai zu sehr die Vorstadt St. Pauli oder gar das benachbarte Altona und nicht das eigentliche Hamburg geschäftlich beleben ${ }^{54}$. Im Bedenken über die Solidität der neuen Kaimauer und überhaupt aller Hafenpläne wandte man sich an die holländische Regierung, den besten verfügbaren Wasserbaufachmann zu senden. Der holländische Wasserbauinspektor Mentz fällte nicht nur ein anerkennendes Urteil über die Kaimauer, was den Streit zwischen Rat und Bürgerschaft schlichtete,

von Untiefen in den Flußmündungen sowie über die ganze mechanische Naßbaggerei, hat aber aus Besichtigungen und Gesprächen mit Englands führenden Ingenieuren Thomas Telford und Robert Stephenson auch Ideen für das Hamburger Hafenprojekt mitgebracht.

${ }^{51}$ Charles Vignoles, Bericht an den S. T. Herrn Syndikus Kauffmann, Präses einer hochlöblichen Schiffahrts- und Hafendeputation etc. (Abschrift des Hafenbauprojektes vom März I836). - Akten der Schiffahrts- und Hafendeputation, StA Hamburg, D. 487.

52 Text des Senats-Propositums bei MacElwee, Hamburgs Hafenbaupolitik a. a. O., S. 2 I.

${ }_{53}$ Griese, Hamburger Hafen a. a. O. S. 20. - MacElvee, Hamburgs Hafenbaupolitik a. a. O. S. 27. - Eine Tauchglocke diente erstmals dazu, die Pfahlstummel ausfindig zu machen, die unter Wasser herausgezogen werden mußten. Bei der Abtragung der Johannisbastion wurden insgesamt über 7000 solcher Pfähle gezogen, was rein technisch damals etwas Besonderes bedeutete. Auch später hat die Taucherglocke noch Tausende von Pfahlstummeln im Hafen beseitigt und beim Versetzen der Dückdalben geholfen. Die Glocke konnte bis zu I 8 Fuß tief tauchen und bezeichnet den Beginn des Tauchwesens im Hamburger Hafen, das heute von großen Firmen wahrgenommen wird. Die älteste konnte vor kurzem ihr einhundertjähriges Bestehen feiern. Die Einübung der deutschen Taucher geschah im übrigen durch schottische Tauchglockenmannschaft der Firma Robert Stephenson.

54 MacElwee, Hamburgs Hafenbaupolitik, a. a. O. S. 29. 


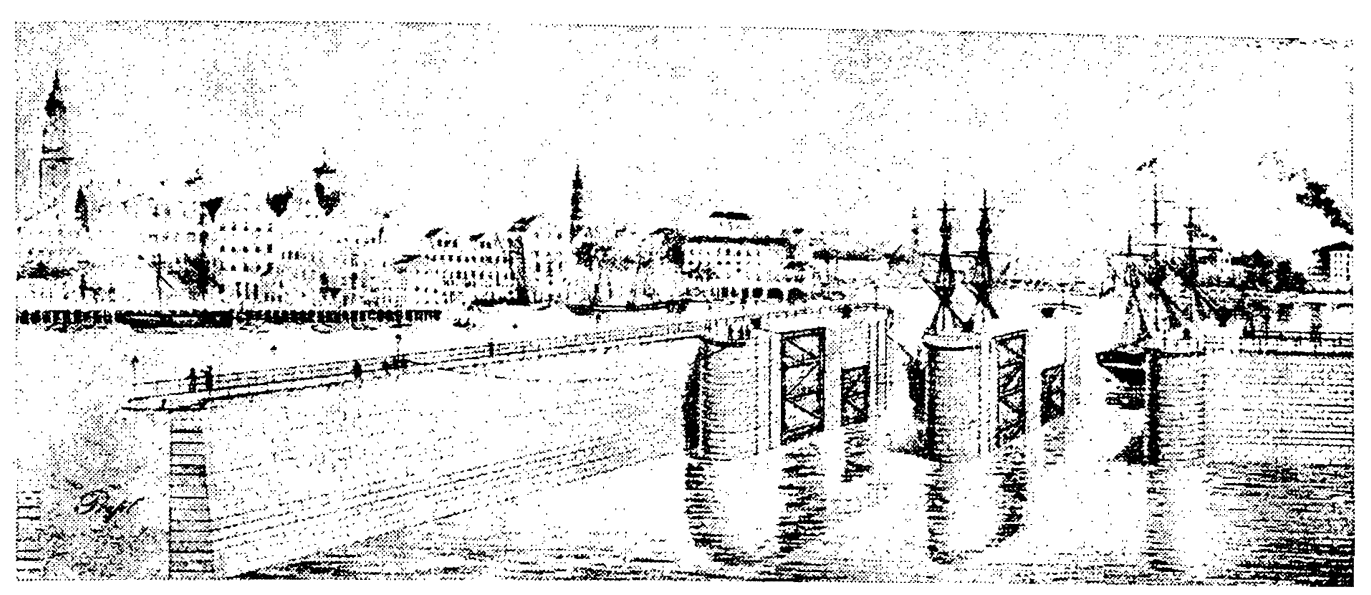

sondern trat selbst mit einem Hafenplan i 840 hervor, der die Vorteile der Pläne Biischs, Woltmanns und Hübbes vereinen wollte. Seine Hauptgedanken waren, Ober- und Niederhafen $z u$ verbinden (was erst 1888 durch den Zollkanal geschah) und die ganze innere Stadt durch ein Schleusen- und Deichsystem so zu umschließen, daß auf sämtlichen Kanälen und Fleeten auch bei Ebbe ein Verkehr möglich war. Aber auch dies war den Hamburgern viel zu weitläufig und zu teuer ${ }^{55}$.

Es sprach aber für die Dringlichkeit, daß schon zwei Jahre nach dem großen Brand von I 842 (der den Hafen nicht in Mitleidenschaft zog) das alte Grasbrookprojekt schon wieder vorgezogen wurde. Vier Forderungen wurden aufgestellt: a) Erweiterung des Oberhafens für die Flußschiffe und des Niederhafens für die Seeschiffe, b) bequeme Verbindung zwischen beiden, c) Verbindung zwischen Niederhafen und dem Bahnhof der Berlin-Hamburger Eisenbahn, d) Bau von Speichern und Löschplätzen in unmittelbarer Kommunikation mit den Seeschiffen ${ }^{56}$. Im Gegensatz zum Ausland empfahl die Commerzdeputation den Hafenausbau als Staatsaufgabe, beim Bau und bei der Verwaltung sollten private Unternehmer ausgeschaltet werden ${ }^{57}$. Sie war es auch, die nach vorheriger Aufforderung des Senats den englischen Ingenieuren James Walker und William Lindley den Auftrag erteilte, »unter umfassender Berücksichtigung der ferneren Entwicklung der Schiffahrt und des Handels« einen eigenen Plan für die Hafenvierbesserung vorzulegen. Unabhängig davon wurde Wasserbaudirektor Hïbbe mit derselben Aufgabe betraut. Außerdem wurde bei den beteiligten Wirtschaftszweigen eine Art von Meinungsbefragung durchgeführt, indem man Zirkulare versandte, in denen spezielle

55 Ebd., S. 3 I.

${ }^{56}$ Vergl. die Abbildung dieses Hafenplans bei Meyer-Marwitz, Hamburgs Weg zum Welthafen a. a. O., S. 38.

57 Dies ist ein sehr wichtiger Gesichtspunkt, wenn man bedenkt, daß viele andere große Welthäfen wic London, Rotterdam oder New York von privaten Unternehmern geschaffen wurden. Vergl. MacElwee, Hamburgs Hafenbaupolitik a. a. O. S. 3 r. 
Wünsche geäußert werden konnten ${ }^{58}$. Der im Oktober I 845 vereint vorgelegte Lindley-Walker-Hübbe-Plan ließ schon in großen Zügen die später gebauten Hafenbecken erkennen ${ }^{59}$. Der Niederhafen wurde durch Schleusen von der Elbe abgetrennt. Von hier aus führte ein Weg zum Vorhafen (No. I), von dort zum Hafen No. 2 und No. 3, von wo man in die Bassins $A, B$ und $C$ gelangen konnte. Alle Häfen waren untereinander sowie vom Ober- wie vom Niederhafen gut zu erreichen, Gleisanschlüsse und Kräne waren geplant. Der Plan scheiterte an dem Hauptfehler, daß er das alte Eindeichungsprojekt gegen die Sturmflut mit dem Hafenausbau verband und so notwendig den Dock-

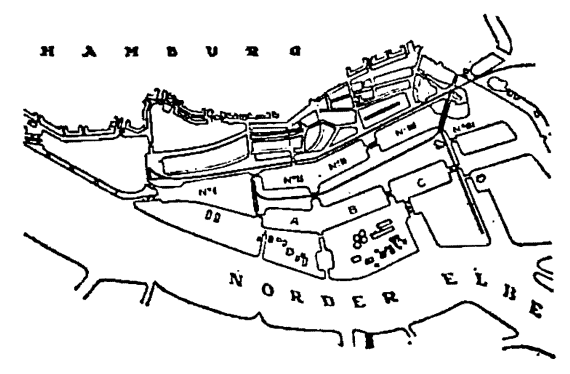

hafen vorschlagen mußte. Befreiung von jährlichen Überschwemmungen und Vermehrung der Schiffsliegeplätze sollten Hand in Hand gehen. Aber das komplizierte Schleusen- und Deichsystem war im Gegensatz zu London, Liverpool, Antwerpen und Le Havre, in Hamburg mit seinem relativ kleinen Unterschied von $2 \mathrm{~m}$ im Wasserstand nicht notwendig ${ }^{60}$. So blieb trotz seiner teilweise geradezu genialen Gedanken der Lindley-Walker-Hübbe-Plan auf dem Papier - zum großen Vorteil Hamburgs, wie sich dann herausstellte.

Zwischen I 852 und 1855 gab es eine Reihe kleinerer Hafenverbesserungen, die bereits in die Richtung offener Tidehafen wiesen. Die neuen Bassins auf dem Grasbrook wurden nach dem Walker-Lindley-Hübbe-Plan angelegt, aber ohne Schleusen. Auch brachte der Abbruch der alten Bastion "Hölzerner Wambs«, des Blockhauses und der alten Neptunsbrücke neben den Pfahlwänden eine merkliche Vergrößerung des Nicderhafens. Die aus den Bassins ausgebaggerte Erde diente zur Erhöhung der Kais gegen die Sturmflut. $\mathrm{Daß}$ die kleineren Erweiterungen sich mehr als drei Jahre hinschleppten, lag an der Tatsache, daß man sich lange nicht über die Akziselinie einigen konnte. Hamburg bekannte sich zum Freihandel, wollte aber auf den »Oktroi« (Akzise und Torsperre) als Einnahme nicht verzichten. Die alten Stadtmauern und die Wassertore Oberbaum und Niederbaum hatten diese Einnahmen gesichert. Die Erklärung Hamburgs zur offenen Stadt, die Einbeziehung der Vorstädte St. Pauli und St. Georg und der Ausbau des vor den Toren liegenden Grasbrooks ließen die alten Zollgrenzen verschwinden. Die »löbliche Cämmerey« hatte daher aus fiskalischen Punkten lange den Hafenausbau bekämpft.

58 Vergl. Denkschrift an den Hochedlen Rat vom 26. März 1 858, S. III.

${ }^{5 \theta}$ Entwurf zur Verbesserung des Hafens von Hamburg unter Benutzung des Grasbrooks - gehörig zum Bericht vom 10. Oktober 1845 .

${ }^{60}$ Wiedenfeldt, Die nordwesteuropäischen Welthäfen a. a. O., S. 72. 
Schließlich einigte man sich, die neue Zollinie zwischen Stadt und neuem Hafen verlaufen zu lassen; der Keim zum Freihafen war damit 1855 schon gelegt. Durch Tausch und Kauf hatte sich der Senat auf gütlichem Weg bereits in den Besitz des ganzen Grasbrooks gebracht, was den Ausbau später unendlich erleichtert hat.

I 857 forderte der Senat die Commerzdeputation erneut auf, die Frage Dock- oder Tidehafen zu untersuchen. Obwohl seit I 828 mit dem Projekt befaßt, ging man noch einmal an die Arbeit und legte schließlich den Plan zu einer Hafeneinrichtung vor, wie er dann verwirklicht wurde. Die Denkschrift von I 858 ist die eigentliche Geburtsurkunde des heutigen Hamburger Hafens. Alle möglichen Sachverständigen vom Reeder und Kapitän über den Hafenmeister bis zum Eisenbahndirektor und Makler waren dazu gehört worden. Der Walker-Lindley-Hübbe-Plan von 1845 wurde gedruckt versandt, i 8 Sitzungen abgehalten und mehr als 40 Personen vernommen, deren Aussagen im Protokoll festgehalten wurden. Alle sprachen sich ohne Ausnahme für den offenen Tidehafen aus $^{61}$. Dies kam den Plänen Johannes Dalmanns, Hübbes Nachfolger als Wasserbaudirektor, sehr entgegen, da er ein eifriger Verfechter des Tidehafens war.

Die Begründung für die Ablehnung der Dockpläne wurde in folgenden Hauptpunkten zusammengefaßt $\mathrm{t}^{62}$ :

I. Die Schiffe können bei gewöhnlichen Stautoren nur bei Flut ein- und ausfahren, so daß beim Öffnen der Tore ein Andrang entsteht. Der Verkehr wird eher gehemmt als gefördert und an einem großen Teil des Tages unterbrochen.

2. Größere Schiffe müssen bei Vorflut den Hafen verlassen, um über die Untiefen bei Teufelsbrück, Blankenese und Schulau zu gelangen. Es ist aber unmöglich, rechtzeitig bei genügend hohem Wasserstand dorthin zu gelangen, wenn sie erst bei Hochwasser aus dem Dock kommen.

3. Die Schuten, die dann auch erst die Docks verlassen können, müßten gegen die starke Ebbe die Waren in die Fleete bringen.

4. Tritt kurz vor oder nach Hochwasser Nebel ein, so kommen die großen Schiffe in eine schlimme Lage, weil sie auf dem Strom nicht ankern können, weil sie dort schnell auf Grund kommen.

5. Selbst Kammerschleusen mit einem Bassin davor erschweren den Verkehr, da ihre Benutzung sehr viel Zeit kostet.

6. In Hamburg spielt im Gegensatz zu England das Eis eine große Rolle, im stillen Dock friert es eher als im Strom.

In der »Denkschrift an einen Hochedlen Rat vom 26. März I 858 « wurden dagegen die Grundgedanken künftiger Hafenbaupolitik in Hamburg durch die Commerzdeputation aufgrund der Befragungen in 16 Punkten niedergelegt. Die wichtigsten davon lauteten:

81 Denkschrift an den Hochedlen Rat vom 26. März i 858. - Gelegentlich wird in den Hamburgiensien der Hamburger Wasserbaudirektor Johannes Dalmann als der eigentliche Vater des modernen Hamburger Hafens bezeichnet, weil er im wesentlichen diese Denkschrift verfaßt hat. Bei den vielen Vorüberlegungen und ähnlichen Plänen wird man allerdings sagen müssen, daß die Denkschrift von 1858 nicht sein alleiniges Verdienst gewesen ist.

62 Siehe Anhang zum Protokoll I 858. 
I. Verlegung der Werften und Kohlenlager nach dem Reiherstieg an das gegenüberliegende Südufer der Elbe,

2. Erweiterung und Umgestaltung des Sandtorhafens und seiner Einfahrt,

3. Herstellung "steinerner Vorsetzen« (Kais) um den Sandtorhafen 20 Fuß unter Null fundiert und is Fuß über Null erhöht,

4. Ausbaggerung des Sandtorhafens und des Niederhafens i 6 Fuß unter Null,

5. Ausstattung des Sandtorkais mit Kränen, Schuppen, Eisenbahngleisen und Fahrstraßen,

6. Herstellung einer Eisenbahnverbindung von den Bahnhöfen zu den Kais,

7. Bau massiver Speicher am Mittelkai des Sandtorhafens sowie zwischen Sandtor-Südkai und Elbkai.

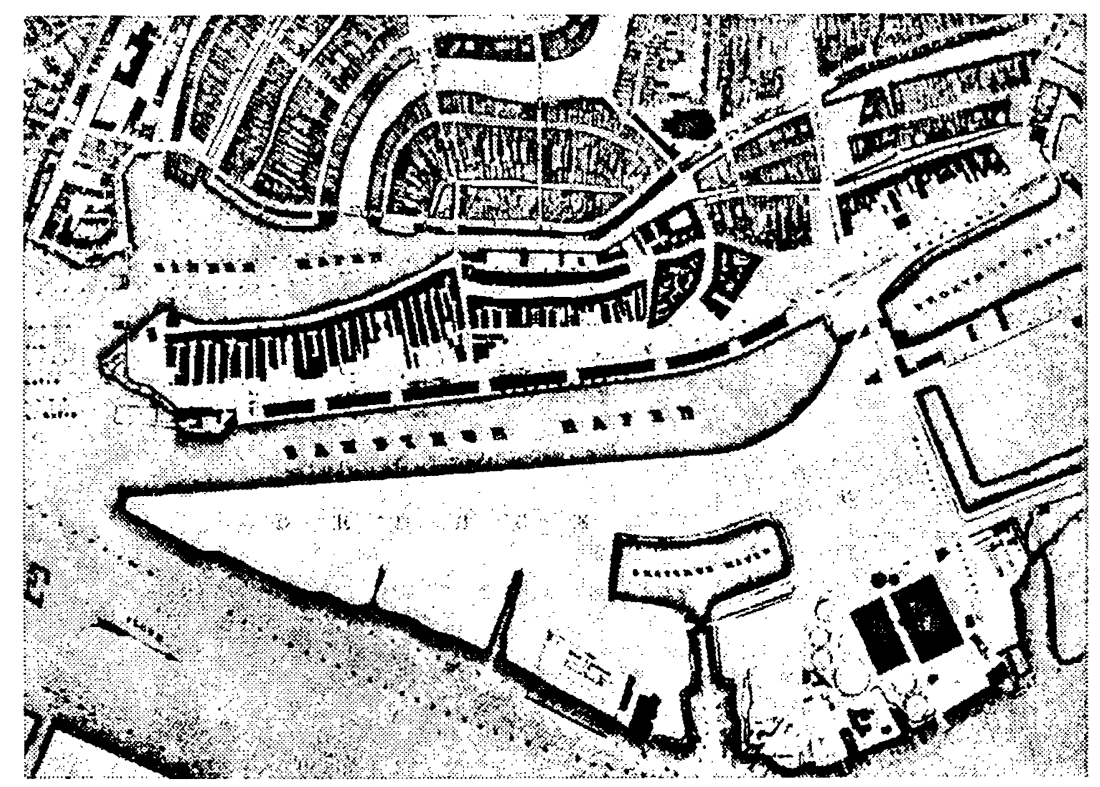

Interessanterweise wurde vom Hafenmeister eine Breite von $200 \mathrm{Fuß}$, also von $70 \mathrm{~m}$, als genügend erachtet, um zwei Reihen von Seeschiffen mit den dazugehörigen Schuten und einer Freilassung eines Durchgangs in der Mitte das Anlegen an den Kais zu gestatten. Auch der Tiefgang wurde mit 5,5 $\mathrm{m}$ sehr klein bemessen; noch ahnte man nichts von den Ozeanriesen der Imperator-Klasse mit 50000-60000 BRT, geschweige heutigen Super-Tankern. Alle Größen wie Kostenvorstellungen wurden in den nachfolgenden Jahren immer wieder überholt. Immerhin war man sich 1858 endgültig über das künftige Hafensystem schlüssig geworden. Interessanterweise wurde das alte Dückdalbensystem nicht ganz aufgegeben. Erz, Kohle, Getreide und andere Massengüter wurden nach wie vor auf dem offenen Strom in die Flußschiffe umgeschlagen und von dort dann ins Inland weiter verschifft. Wertvolle Kaiplätze wurden so erspart und die Löschkosten, die gerade bei Massengütern sehr viel mehr ins Gewicht fallen, niedrig gehalten. 
Umgekehrt konnten andere Schiffe mit der wertvollen Stückgutfracht, wenn sie nicht gerade löschten oder luden, die billigeren Dückdalbenplätze aufsuchen.

Nach wiederholten Memoranden und Eingaben verfügte der Senat I 862 die Inangriffnahme der Arbeiten, mit denen I 863 begonnen wurde. Am I s. August 1866 konnten die ersten Schiffe an dem neuen "Sandthorquai« festmachen. Das erste künstliche Hamburger Hafenbecken mit Schuppen, Kaianlagen und Gleisanschluß war entstanden, der erste Schritt zum modernen Hafen getan. Nimmt man Büschs Plan von 1786 als Ausgangspunkt, so kann man sagen, die Entstehung des Hamburger modernen Hafens brauchte von der ersten Idee bis zur ersten Realisierung achtzig Jahre. Über die technischen Einzelheiten braucht an dieser Stelle nicht im einzelnen referiert zu werden. Der neue Hafen war natürlich ein offener Gezeitenhafen ohne Schleusen, nur am oberen Ende befand sich eine Strömungsschleuse zur Verbindung mit dem Oberhafen. Sie diente nicht zur Überwindung eines Wasserstandes, sondern zur Verhütung einer unerwünschten Strömung. Freilich wurde der Vorsetzen der Kosten wegen nur aus Holz hergestellt und erst 1877 aus massiven Steinen ersetzt. Eisenbahngleise nahe der Uferkante wurden mit fahrbaren Dampfkränen versehen, die dann ab 1898 durch elektrische Kräne ersetzt wurden. Diese sind sogar eine Hamburger Erfindung63. Dahinter bauten sich drei Schuppen von roo, I 20 und I60 m Länge mit I, $3 \mathrm{~m}$ Ladehöhe auf, die sich natürlich bald als viel zu klein erwiesen ${ }^{64}$. Die Schuppen waren nach dem Wasser hin offen, an beiden Enden aber geschlossen und standen mit dahinterliegenden Eisenbahngleisen und Fahrstraßen in Verbindung. Die Kaischuppen waren bis auf den Fruchtschuppen alle einstöckig. Dies war notwendig, weil die Waren nur kurze Zeit lagerten und infolgedessen beständig Betrieb herrschte. Bei zweigeschossigen Schuppen hätte man das Tageslicht durch die Decke nicht ausnutzen können und wäre dauernd auf künstliches Licht angewiesen gewesen, das zu

${ }^{63}$ Die hochinteressante Geschichte der Kaikräne kann hier nur gestreift werden. Bis zur Eröffnung des Sandtorkais benutzte man wie in allen Jahrhunderten zuvor einfache Winden mit Handbetrieb. Aufgrund einer öffentlichen Ausschreibung entschied man sich dann für die Anschaffung von Dampfkränen, die man aus England bezog. Nach ihrem Erfinder wurden sie »Brownsche Kräne« genannt. Diese Dampfrollkräne liefen auf Schienen, die ins Pflaster eingelassen waren, wurden aber noch mit der Hand vorwärtsbewegt. Jeder Kran hatte einen eigenen Kessel und eine eigene Dampfmaschine, die einen ziemlichen Lärm machte. Die Tragfähigkeit lag zwischen I,5 und 2,5 t, die Ausladung zwischen 6,4 und 8,6 m. Sehr schnell erkannte man, daß es unrentabel war, daß sich jeder Kran gesondert mit der notwendigen Energie versorgte. Wenn ein Kran arbeiten sollte, mußte erst der Kessel angeheizt werden. Als nächsten Schritt schloß man daher eine Reihe von Kränen an eine zentrale Kesselanlage an, die über Rohrleitungen die Kräne mit Dampf versorgte. Die Fahrbarkeit war deshalb, obgleich die Dampfrollkräne in Halbportalkräne umgewandelt wurden, recht begrenzt. Seit I 894 wurde, angeregt von Siemens' elektrischen Aufzügen, an elektrischen Kränen experimentiert. Aber erst fünf Jahre später war man soweit, um sie auch am Sandtorkai zu installieren. Der Nutzen lag darin, daß sie nicht nur geräuschlos und billiger arbeiteten, sondern jederzeit betriebsklar waren. Voraussetzung für die elektrischen Kräne, die nur die zum Heben und Fahren notwendige Energie verbrauchten, war natürlich die Fertigstellung einer elektrischen Zentralstation im Hafen. Nach Versuchsbeleuchtungen ab I 884 war der Hamburger Hafen um I 890 schon weitgehend elektrisch beleuchtet. Die Elektrifizierung wird von mir im Rahmen einer Geschichte der Hamburgischen Electricitätswerke noch gesondert dargestellt werden. Vergl. Bosselmann, Entwicklung der Kaikrane im Hamburger Hafen a. a. O. S. 35 ff. - Bericht über electrische Kräne, in: Hamburger Correspondent v. 5. Mai r 899. Wendemuth-Böttcher, Der Hafen von Hamburg a. a. O. S. 9 r.

64 Bubendey-Lorenzen, Hamburger Hafen a. a. O., S. 39. 
dieser Zeit bei der Innenbeleuchtung gerade vom Kerzen- zum Petroleumlicht überging. Die Gasbeleuchtung steckte in Hamburg noch in den Anfängen. Außerdem wäre bei zweigeschossigen Bauten viel Platz durch Stützpfosten, Aufzüge und Treppen entfallen. Interessanterweise entschied man sich zunächst nach englischem Beispiel für Eisenkonstruktionen, ging dann aber zur billigeren Holzbauweise über. Da Brände trotz aller Vorkehrungen doch nicht immer zu vermeiden waren, war es besser, wenn die Schuppen gleich ganz abbrannten, um kostspielige Abbrucharbeiten zu vermeiden. Auch auf kostspielige Fußböden wurde verzichtet und das Fundament gleich auf das Erdreich gelegt. Bei Senkungen schüttete man einfach Sand nach. Da die Ladungen in der Regel sehr unterschiedlich waren, dienten die Schuppen vor allem zum Sortieren und nur der kurzfristigen Lagerung. Von hier $\mathrm{kam}$ sie in die Schuten oder Flußschiffe bzw. in die Eisenbahn und Fuhrwerke, die vor den großen Schiebetüren
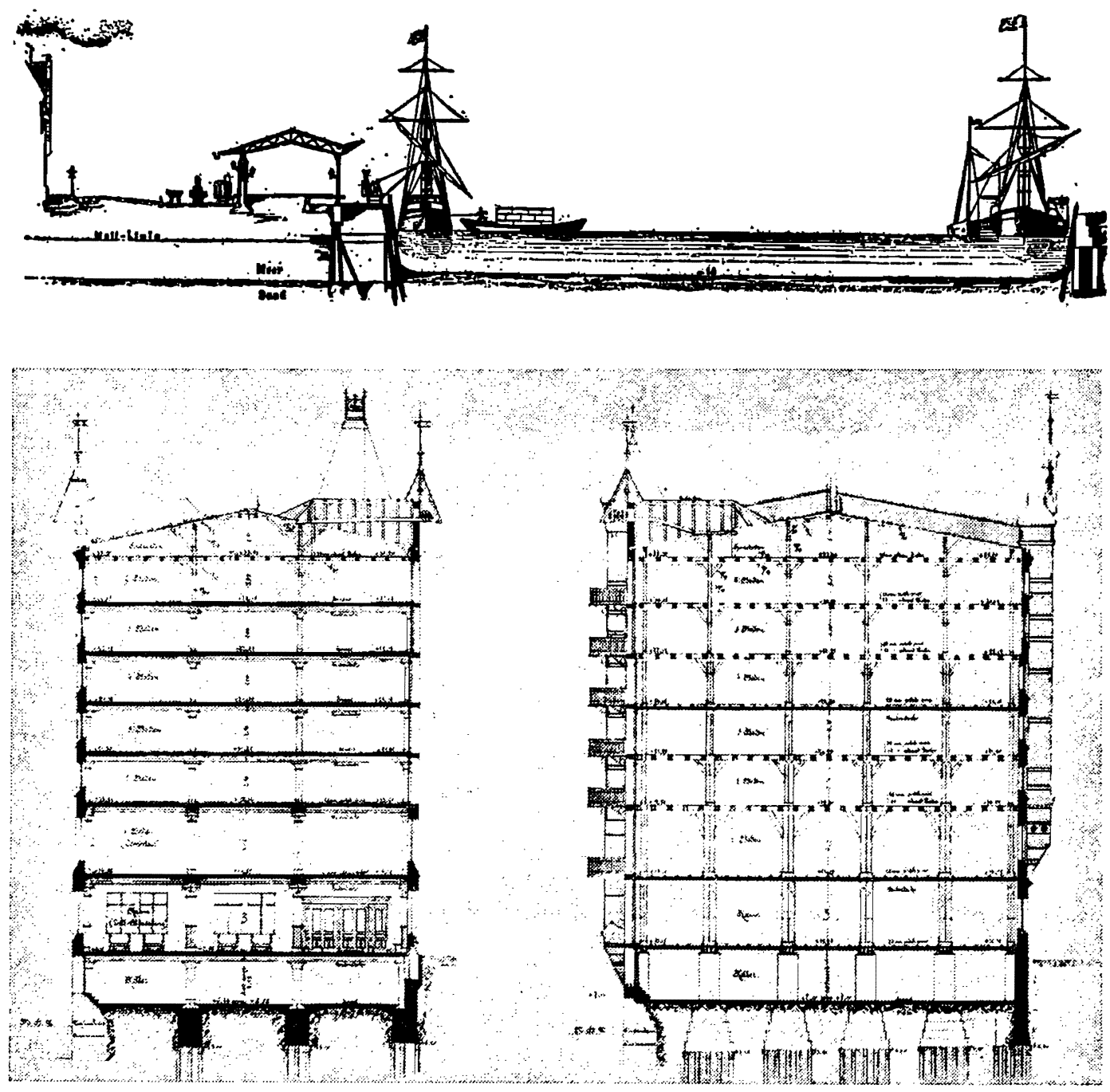


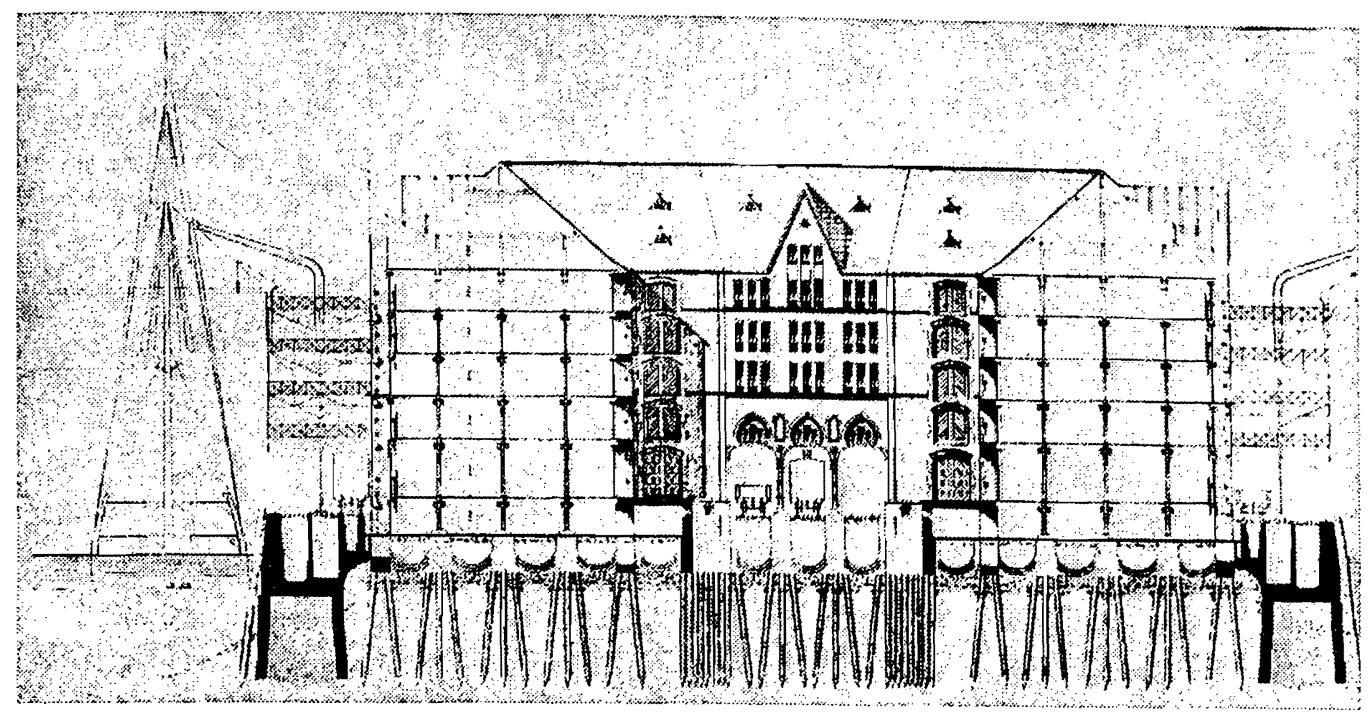

hielten. Sollte ein Gut länger gelagert werden, brachte man es zu den kleinen Speichern an den Fleeten der Innenstadt. Der Bau massiver Speicher begann erst nach dem Zollanschluß. Die Güter wurden meistens mit dem Handkarren bewegt. Er ist heute durch Elektrokarren und Gabelstapler abgelöst worden.

Die Umschlagtechnik Seeschiff - Schute - Speicher, Seeschiff - Flußschiff und Seeschiff Schuppen - Fuhrwerk - Eisenbahn bewährte sich und blieb bis heute. Der Sandtorkai wurde vor allem von Dampfschiffen angelaufen, die so schnell wie möglich laden und löschen wollten. Die Zahl der dort anlegenden Schiffe wuchs von 1867-1869 von 665 auf 68s und die Zahl der Kommerzlasten von 139317 auf I5 $1698^{65}$. Als wirtschaftliche Fehlplanung erwies sich der Kaiserspeicher. Er war so gebaut, daß die Schiffe gleich ohne Umweg über den Schuppen in den Speicher löschen konnten. $\mathrm{Da}$ aber die Stückgüter in gemischtcn Ladungen ankamen und an verschiedene Empfänger konsigniert waren, bewährte sich dieser Weg einer Transportkostenersparung nicht. Diese Speicherform wurde nicht mehr gebaut.

Nach dem Ausbau des Sandtorhafens ging es weiter zügig voran. Seit der Einführung der Petroleumlampe hatte die Erdöleinfuhr stark zugenommen. Aus Platzmangel löschten die Petroleumschiffe anfangs zwischen den anderen Seeschiffen. Als man die Gefährlichkeit der Ladung erkannte, wurden diese ersten »Tanker« auf das Südufer der Elbe in den abgelegenen Petroleumhafen verbannt. Für den Bau bewilligte der Senat 1869 das nötige Geld. Als der Platz nicht mehr ausreichte, wurde I 912 an der Insel Waltershof ein neues Bassin für diese Schiffe eröffnet. Nachdem der alte Grasbrook durch Hafenbauten voll in Anspruch genommen war, fing man an, auch die bis dahin überschwemmten Elbinseln auszubauen. Vom Alsterhafen wurde nun endgültig der 8s Mac Elvvee, Hamburger Hafenbaupolitik a. a. O., S. 6I - Eine Hamburger Kommerzlast betrug Gooo Hamburger oder 627,75 preußische Gewichtspfund. 
Schritt zum Elbehafen getan. Auch das südliche Elbegebiet um Steinwärder wurde bald ins Auge gefaßt. Durch den Eisenbahnbau gewann dies früher abgelegene Gebiet verkehrswirtschaftliche Bedeutung. I872 wurde die Eisenbahn von Stade nach Cuxhaven verlängert. Vorher war die Hamburg-Venloer Eisenbahn in Betrieb genommen worden. Die neuen Häfen wurden, um das Bugsieren der großen Seeschiffe zu erleichtern, im Gegensatz zu New York und anderen großen Häfen gleich fächerförmig angelegt. Jeder Hafen erhielt eine Strömungsschleuse und wurde an einen Ring von Kanälen angeschlossen, auf dem sich der Verkehr der Flußschiffe abspielte, die so nicht den Seeschiffsverkehr behinderten. An der Mündung der Häfen von Kuhwärder, Roß, Neuhof und Waltershof wurde noch ein zusätzlicher Vorhafen gebaut, um das Wenden zu erleichtern. Dabei darf allerdings nicht übersehen werden, daß es bis zum Beginn der achtziger Jahre noch beim Sandtorhafen und dem Grasbrookhafen, also zwei auf dem rechten Ufer der Elbe gelegenen Bassins, geblieben ist. Beim Zollanschluß besaß Hamburg mit diesen beiden Becken erst 4I I $3 \mathrm{~m}$ Kailänge und rd. 66000 qm Lagerfläche ${ }^{66}$. Der eigentliche Hauptausbau und Aufschwung begann also erst ganz am Ende des Jahrhunderts.

Trotz des Ausbaus der Hafenanlagen wuchs die Tonnagezahl der Schiffe aber noch schneller. Zwischen 1882 und 1908 stieg die Zahl der Liegeplätze im Hamburger Hafen zwar um r70,6 v.H., die Zahl der Seeschiffe nur um r6s v.H., die Größe der Schiffsgefäße aber um 293 v.H. ${ }^{67}$. Auch an der Entwicklung der Kaischuppen läßt sich die Zunahme des Umschlags illustrieren: So wuchs die Breite der Schuppen von $14,8 \mathrm{~m}$ im Jahre 1866 auf $42 \mathrm{~m}$ im Jahre 1907 und die Länge im gleichen Zeitraum von I70 $\mathrm{m}$ auf $270 \mathrm{~m}^{68}$. Die Anzahl der Kräne vermehrte sich bis I9I I auf insgesamt 806 Hebevorrichtungen, darunter 237 Dampfkräne von 1,5-2,5 t und 332 elektrische Kräne mit 2,5-3 t Tragfähigkeit. Auch verfügen wir über anschauliche Statistiken über den angekommenen und abgegangenen Warenverkehr in Hamburg zwischen I 846 und I906, aus dem sich revolutionierende Bedeutung des Hafenausbaus ablesen läß $\mathrm{t}^{69}$. Aus ihnen läßt sich auch ersehen, daß trotz enorm steigender Bedeutung der Binnenschiffahrt für den Hamburger Hafenumschlag die Eisenbahn, die ihr Hafennetz auf $214 \mathrm{~km}$ crhöhtc, dic Transportleistung im ankommenden Warenverkehr 1906 fast auf gleiche Höhe bringen konnte.

${ }^{86}$ F. A. Meyer, Speicher und Schuppen in Seehäfen (7 Berichte) in: Wiedenfeld, Nordwesteuropäische Seehäfen a. a. O., S. I I I.

${ }_{67}$ Bubendey-Lorenzen, Hamburger Hafen a.a. a. O., S. 24.

${ }_{68}$ Wendemutb-Böttcher, Der Hafen von Hamburg a. a. O., S. 86.

68 Vergl. dazu folgende Statistik:

\section{In Hamburg angekommener Warenverkebr in $t$}

$\mathrm{Jahr}$

1846

1856

1866

1876

I 886

1896

1906
Seeschiff

520000

I 118000

I 149000

2372000

3410000

7104000

12751000

Flußschiff

492000
845000
929000
2009000
2023000
3568000

Eisenbahn

407000

I 58000

270000

864000

I 443000

I 934000

3288000 
Es würde wahrscheinlich nur noch den Techniker interessieren, den Hafenausbau in allen Einzelheiten weiterzuverfolgen ${ }^{70}$. Den mehr an den Grundlinien interessierten Wirtschaftshistoriker beschäftigen in diesem Zusammenhang andere Fragen, z. B. nach den Kosten für den Hafenausbau und wie diese sich zum Hamburger Gesamtbudget verhalten haben. Angesichts des Fehlens solcher Statistiken ist dieses Problem natürlich ebenso schwer zu beantworten wie die spiegelbildliche Frage, wieviel Einnahmen der moderne Hamburger Hafen Bürgern auf der anderen Seite zusätzlich zugeführt hat. Die Schwierigkeiten einer exakten Berechnung liegen vor allem darin, weil nicht nur die Ausgaben des ordentlichen Haushalts, wie Löhne und Gehälter, Bauten, Neuanschaffungen, Unterhaltung, Baggerei, Baumaterialien usw., sondern auch vor allem die Anleihen und Zinsen im außerordentlichen Haushalt berücksichtigt werden müssen. Fast alle Hafenbauten sind auf dem Wege staatlicher Anleihen finanziert worden, ganz im Gegenteil zu England und den USA, wo dies privaten Aktiengesellschaften überlassen wurde. Nach verschiedenen Berechnungen (die von verschiedenen Zeitpunkten und verschiedenen Faktoren ausgehen) dürften die Gesamtkosten zwischen 1837 und 1913 522,7 Mill. Mk. bzw. zwischen 1858-1907/12 um ${ }_{469}$ Mill. Mk. betragen haben ${ }^{71}$. Die Zahlen basieren in der Hauptsache auf den beII. In Hamburg abgegangener Warenverkebr in $t$

$\begin{array}{lrrr}\text { Jahr } & \text { Seeschiff } & \text { Flußschiff } & \text { Eisenbahn } \\ 1846 & 215000 & & 375000 \\ 1856 & 460000 & 436000 & 173000 \\ 1866 & & \text { Keine Statistik vorhanden } & 635000 \\ 1876 & 726000 & 393000 & 681000 \\ 1886 & 1835000 & 1036000 & 905000 \\ 1896 & 3241000 & 2908000 & 5008000 \\ 1906 & 6193000 & 1764000\end{array}$

${ }^{0}$ Eine ausführliche Chronologie über den weiteren Hafenausbau in technischer Hinsicht findet sich bei MacElwee, Hamburger Hafenbaupolitik a. a. O.

${ }^{11}$ Bubendey-Lorenzen, Hamburger Hafen a. a. O., S. 90, kommt zu folgender Berechnung über die Kosten des Hamburger Hafens:

\begin{tabular}{|c|c|c|c|}
\hline I 859-1868 & \multicolumn{3}{|c|}{ 2I,4 Mill. M } \\
\hline I $869-1878$ & 33,5 & ", & , \\
\hline I $879-$ I 888 & 108,6 & ", & " \\
\hline I $889-$ - 898 & 165,3 & $"$ & , \\
\hline $1899-1907$ & I 40,4 & 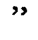 & " \\
\hline Zusammen & 469,2 & & $\lambda$ \\
\hline
\end{tabular}

In diesen Zahlen sind die Rückerstattungen des Deutschen Reiches nach dem Zollanschluß-Vertrag in Höhe von 40 Mill. $M$ bereits enthalten. Von dieser Gesamtsumme entfielen 349,2 Mill. M auf den Hafenausbau, I 20 Mill. $M$ auf die Elberegulierung.

MacElwee, Hamburger Hafenbaupolitik, S. ror, kommt auf folgende Rechnung:

Jahr

$1837-1853$

$1853-1863$

$1863-1873$

I $873-1883$

I $883-1893$

I $893-1903$

I903-I913

Zusammen

Anleihe
1640000 M
$5666450 "$
$9078500 "$
$2822000 "$
$133632500 "$
$77668300 "$
$131083100 "$
$361590850 \mathrm{M}$

Budget

$8820670 \mathrm{M}$

9412824"

$8528290 "$

IS I99000"

23200000 "

$37298391 "$

5863 159x"

I61090771 $M$ insgesamt $522681621 \mathrm{M}$

Die Kosten MacElwees sind höher als die von Bubendey-Lorenzen, weil hier auch der Ausbau des Hafens von Cuxhaven einbezogen wurde. 
reitgestellten Geldern in Form von Anleihen, nicht auf den tatsächlichen Ausgaben. Aber die absolute Höhe besagt nicht viel. Man bekommt erst eine Anschauung von den Größenverhältnissen, wenn man erfährt, daß der Bremer Hafenausbau zwischen I 859 und I9I 2 nur insgesamt 92,2 Mill. Mk. beanspruchte ${ }^{72}$. Die Aufwendungen für den Hamburger Hafenbau schluckten zwar 40 v.H. des außerordentlichen Etats, überschritten aber nach den Statistiken niemals i4,2 v.H. (1854) des ordentlichen Haushalts und bewegten sich ab 1869 durchschnittlich nur noch um 4 V.H. Schon I9I0/ri deckten die laufenden Einnahmen aus dem Hafenbetrieb nicht nur die Unterhaltung und die Neuanschaffungen, sondern brachten sogar einen Gewinn von über I Mill. Mk. jährlich ${ }^{73}$. Die solide Finanzierung und schnelle Amortisation ist wohl eine der erstaunlichsten Tatsachen an der Geschichte des Hamburger Hafens.

\section{Der Zollanscbluß und der Bau des Freibafens}

Die Entstehung des Hamburger Großhafens ist auf das engste mit dem Beitritt der Stadt zum Deutschen Zollverein verbunden. Es ist aber an dieser Stelle nicht möglich, auf alle bis in das 17. Jahrhundert zurückgehenden Bestrebungen für einen "porto franco" und auch nicht auf Hamburgs wechselnde Stellung zum Zollverein und zum Plan einer österreichisch-deutschen Zollunion einzugehen. Hierüber gibt es bereits ausführliche historische Studien ${ }^{74}$. Das Problem der Zölle lautete vor einhundert Jahren knapp zugespitzt wie folgt: Aus den verschiedensten Gründen fand im Deutschen Reich Ende der siebziger Jahre die hochliberale Phase ein Ende und ein Übergang zum Schutzzollsystem statt. Einesteils wurden die Schutzzölle für bestimmte Zweige der eigenen aufstrebenden Industrie, vor allem aber für die Landwirtschaft gebraucht, die von dem billigen amerikanischen Weizen bedroht wurde, nachdem die ungeheuren jungfräulichen Getreidefelder im Westen der USA durch Eisenbahn und Dampfschiff an den Weltverkehr angeschlossen worden waren. Schließlich waren die Zölle wichtig für das Reich, das sonst von den Zuschüssen der Bundesstaaten abhängig war. In Hamburg überstieg in der Jahrhundertmitte die Einfuhr, vor allem die englische, noch bei weitem die Ausfuhr ${ }^{75}$. Trotz langsamen Wachstums des deutschen Industrieexports auf dem Seewege dominierte auch in der zweiten Hälfte der siebziger Jahre immer noch der großbritannische Handel in Hamburg mit 28,5 bzw. 24,3 v.H. des Gesamtimports und 28 v.H. des Gesamtexports ${ }^{76}$. Noch immer war also Hamburg überwiegend nach England ausgerichtet und der große nordeuropäische Vermittlungshafen dorthin. Im Gegensatz zu Lübeck, das sich bereits 1866 dem Zollverein angeschlossen hatte, zeigte Hamburg ebenso wie Bremen wenig Neigung, sich zollmäßig ins Reich

72 Fliggel, Die deutschen Welthäfen, a. a. O., S. I64.

${ }^{23}$ MacElwee, Hamburger Hafenbaupolitik a. a. O., S. ror ff.

${ }^{24}$ Vergl. u. a. Baascb, Geschichte Hamburgs a. a. O. - Ebrenberg, Anfänge des Hamburger Freihafens a. a. O. Wiskemann, Hamburg und die Welthandelspolitik a. a. O. - Wiedenfeldt, Die nordwesteuropäischen Welthäfen a. a. O. - Schramm, Hamburg-Deutschland und die Welt a. a. O.

${ }^{25}$ Vergl. die instruktiven Statistiken bei Wiskemann, Hamburg und die Welthandelspolitik a. a. O., S. 2 Ir. ${ }^{76}$ Ebd., S. 2 I 2. 


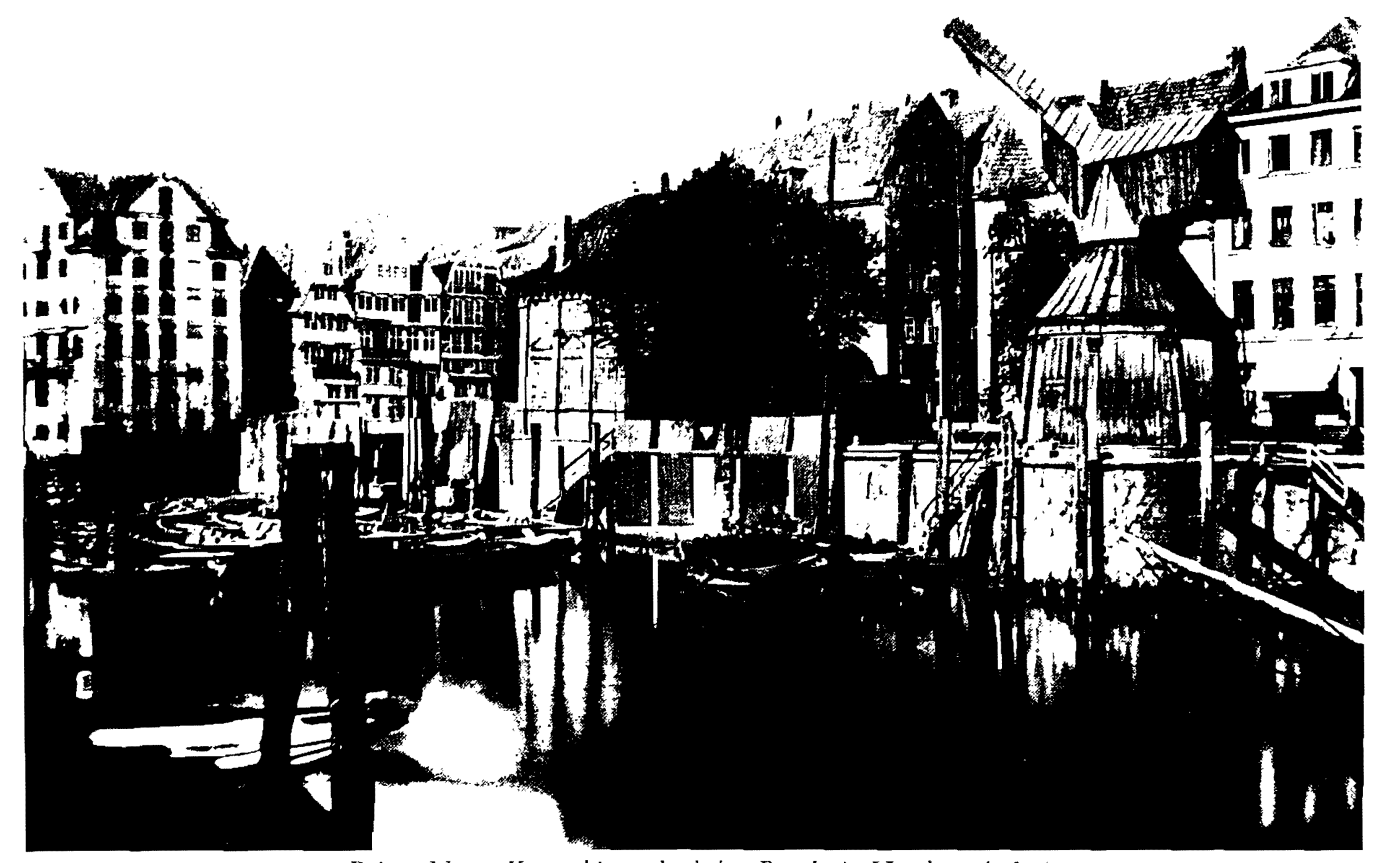

Beim "Nenen Kranu binter der boben Bricke in Hamburg (1856)

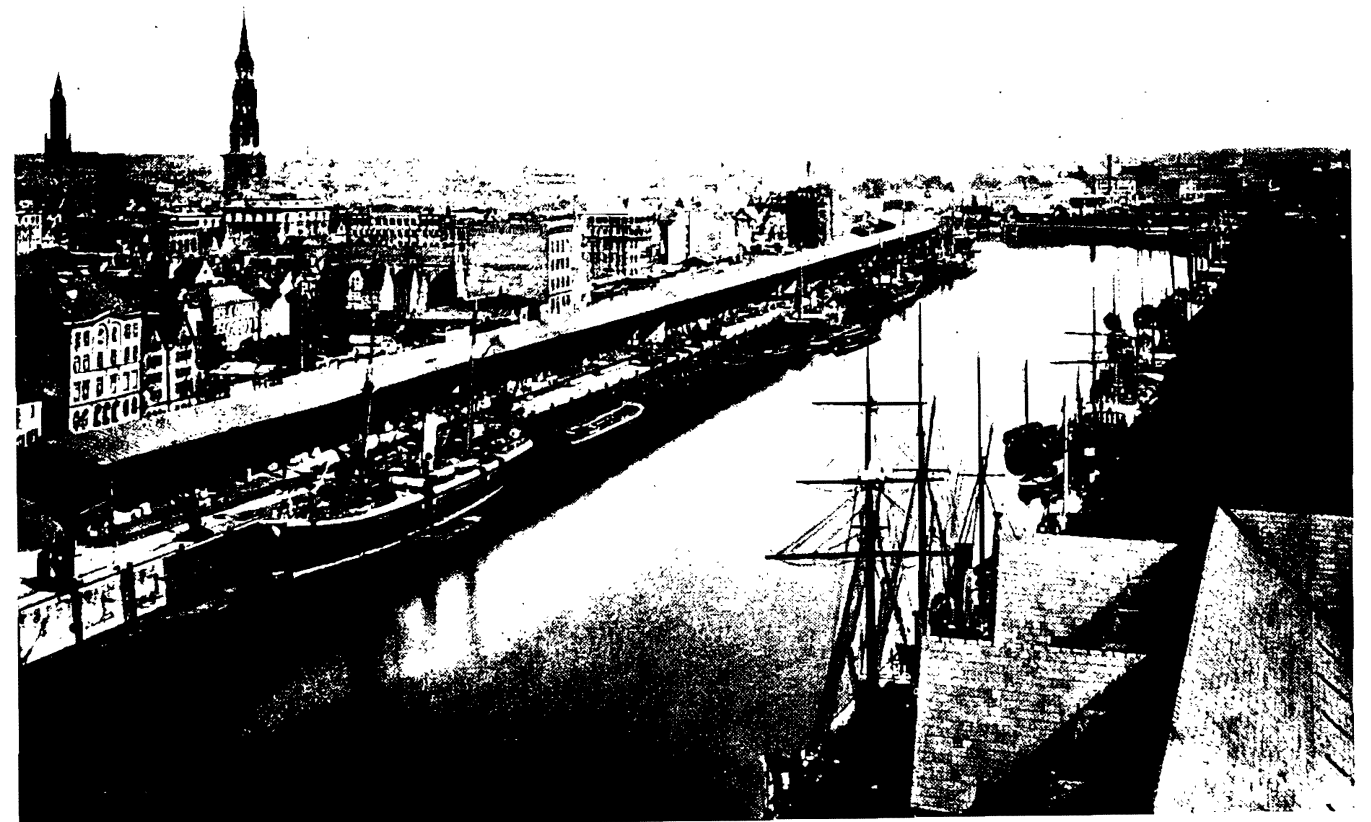

Sandtorbafen vom Kaispeicber geseben ( 1877 ) 


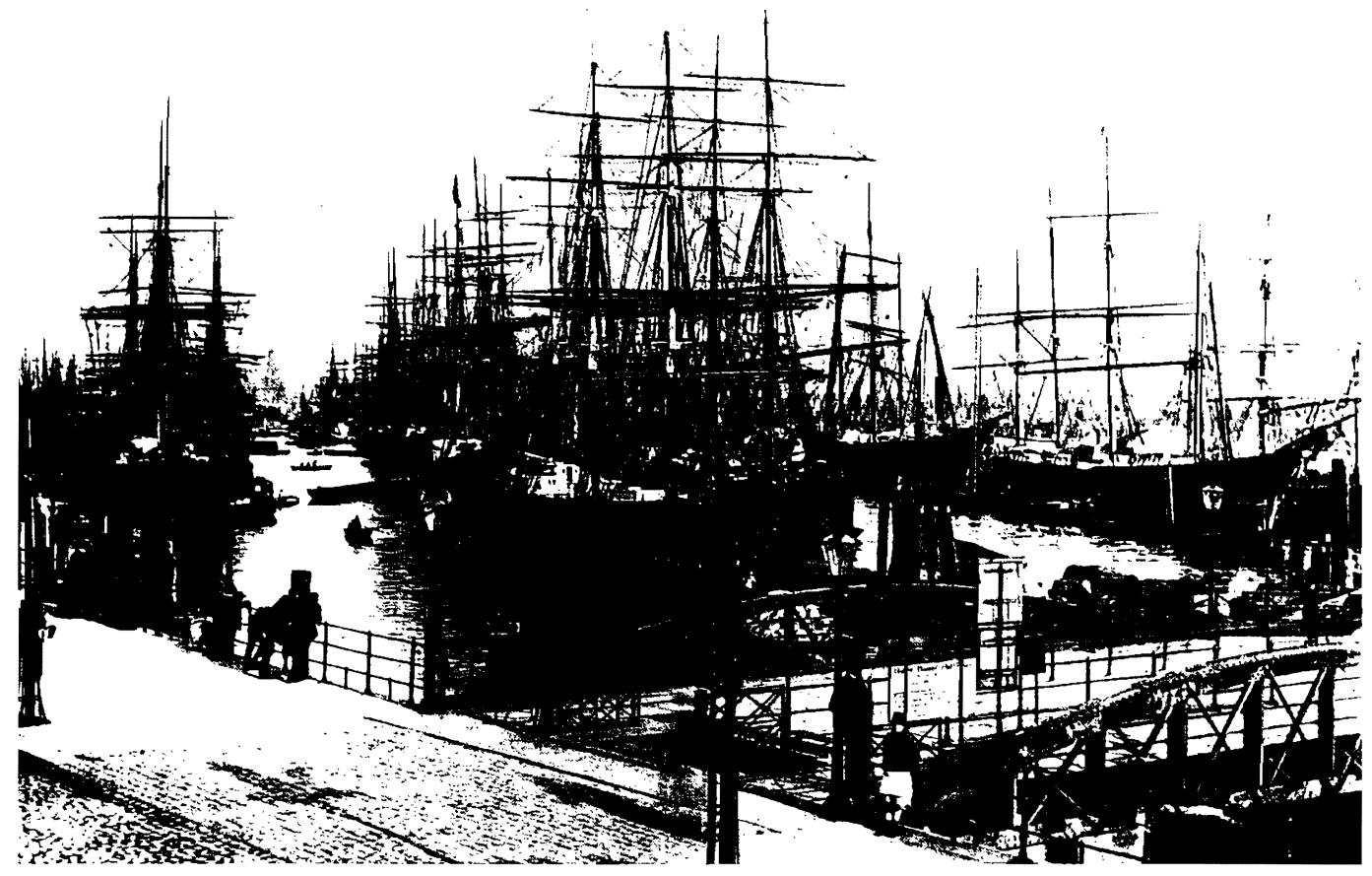

Jonashafen $11 \mathrm{~m}$ I 887

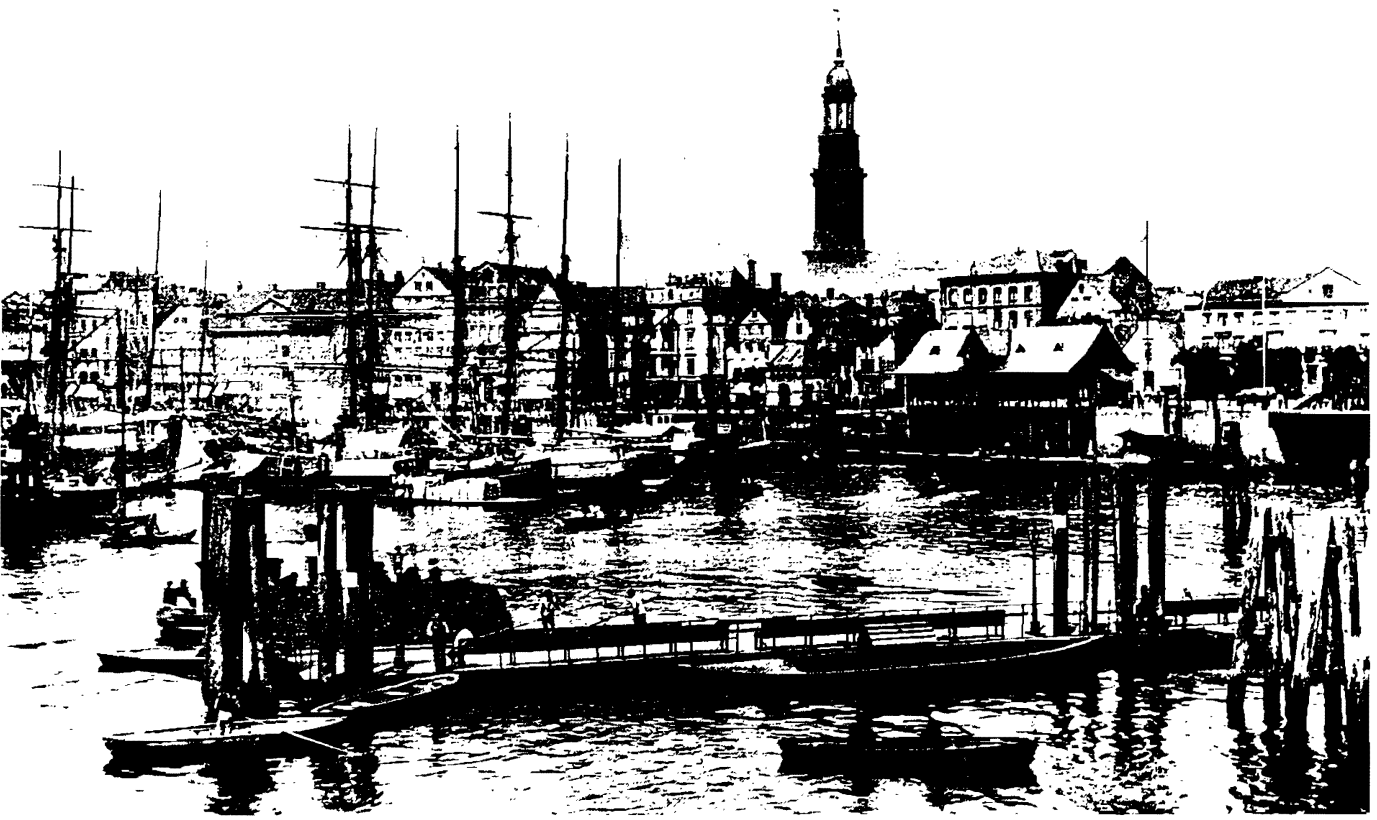

Hamburger Hafen um 1900 nach dem Ende des ersten Ausbaus 
hineinziehen zu lassen und seine Stellung als "porto transito« aufzugeben. In der Reichsverfassung von I 870 hatte sich Hamburg ausdrücklich das Recht vorbehalten, so lange Zollausland zu bleiben, bis es selbst den Antrag zu einer Änderung stellen würde. Bismarck betrachtete natürlich die Freihafenstellung nur als vorübergehende Ausnahmestellung und richtete seine ganzen Bemühungen darauf, die beiden Hansestädte mit den deutschen Handelsinteressen, vor allem die der exportierenden Industrie zu verbinden. Der Kanzler vermied zwar jede Rechts- oder Verfassungsverletzung, benutzte aber jedes legale Mittel, um schärfsten Druck auf Zollanschluß auszuüben. Unversöhnlich standen sich auch in Hamburg selbst wie im Reich Zollanschlußanhänger und ihre Gegner gegenüber. Ein Kompromiß wurde erst erreicht, als Bürgermeister Kirchenpauer als Vertreter des konservativen »alten Hamburgs« im April I 880 aus dem Bundesrat ausschied und sein wendiger Nachfolger Versmann unter Wahrung berechtigter Interessen einen Kompromiß zwischen deutscher und Hamburger Handelspolitik erreichte. Die Kommerzdeputation machte den Vorschlag, das vorhandene und zukünftige Hafengebiet als Zollausland abzugrenzen, das übrige Hamburger Staatsgebiet aber dem deutschen Zollgebiet anzugliedern. Im einzelnen wurde gefordert ${ }^{77}$ :

I. Fortbestand eines verkleinerten Freihafens mit Einschluß von Teilen des Elbstromes.

2. Aufgabe der Speicher im Stadtgebiet, soweit sie Güter beherbergten, die zur Weiterbeförderung bestimmt waren. Dafür Bau neuer Speicher am Sandtor- und Grasbrookhafen.

3. Zulassung von Exportindustrie im Freihafengebiet.

4. Übertragung der Zollabfertigung und des Abfertigungsverfahrens an eine dem Hamburger Senat zu unterstellende Behörde.

5. Bau neuer Hafenanlagen am Südufer der Elbe zur Vergrößerung der Schiffsliegeplätze.

6. Bau von Zollsperren quer über die Elbe, da der Strom mitten durch das Freihafengebiet führte.

7. Gewährung eines angemessenen Beitrags von seiten des Reiches zu den Kosten des Zollanschlusses.

Außerdem wurde die Aussiedlung der gesamten Bevölkerung im künftigen Freihafengebiet beantragt.

Alle diese Punkte konnte Hamburg im Vertrag vom 25. Mai 188 I durchsetzen. Am 2I. I. I 882 sprach sich der Reichstag dafür aus, 40 Mill. Mk. Zuschuß zu den Zollanschlußkosten zu geben. Zurück blieb nur eine Stimmung gegen Bismarck, die sich in den nächsten Reichstagswahlen auswirkte. Zwischen I88 I und I883 waren nacheinander drei Kommissionen unter Vorsitz von Bürgermeister Petersen tätig, um einen Generalplan zur Durchführung des Anschlusses zu entwerfen. Nach langen Diskussionen, an der sich auch die Presse lebhaft beteiligte, entschied man sich schließlich

${ }^{2}$ Baasch, Geschichte Hamburgs Bd. 2 a. a. O., S. I55. - A. Woblwill, Aus drei Jahrhunderten a. a. O. S. I 57. Hermann Eberslein [Hrsg], Hamburgs Anschluß an das deutsche Zollgebiet. Verhandlungen zwischen Senat und Bürgerschaft (Stenographische Berichte), Hamburg I88I. 


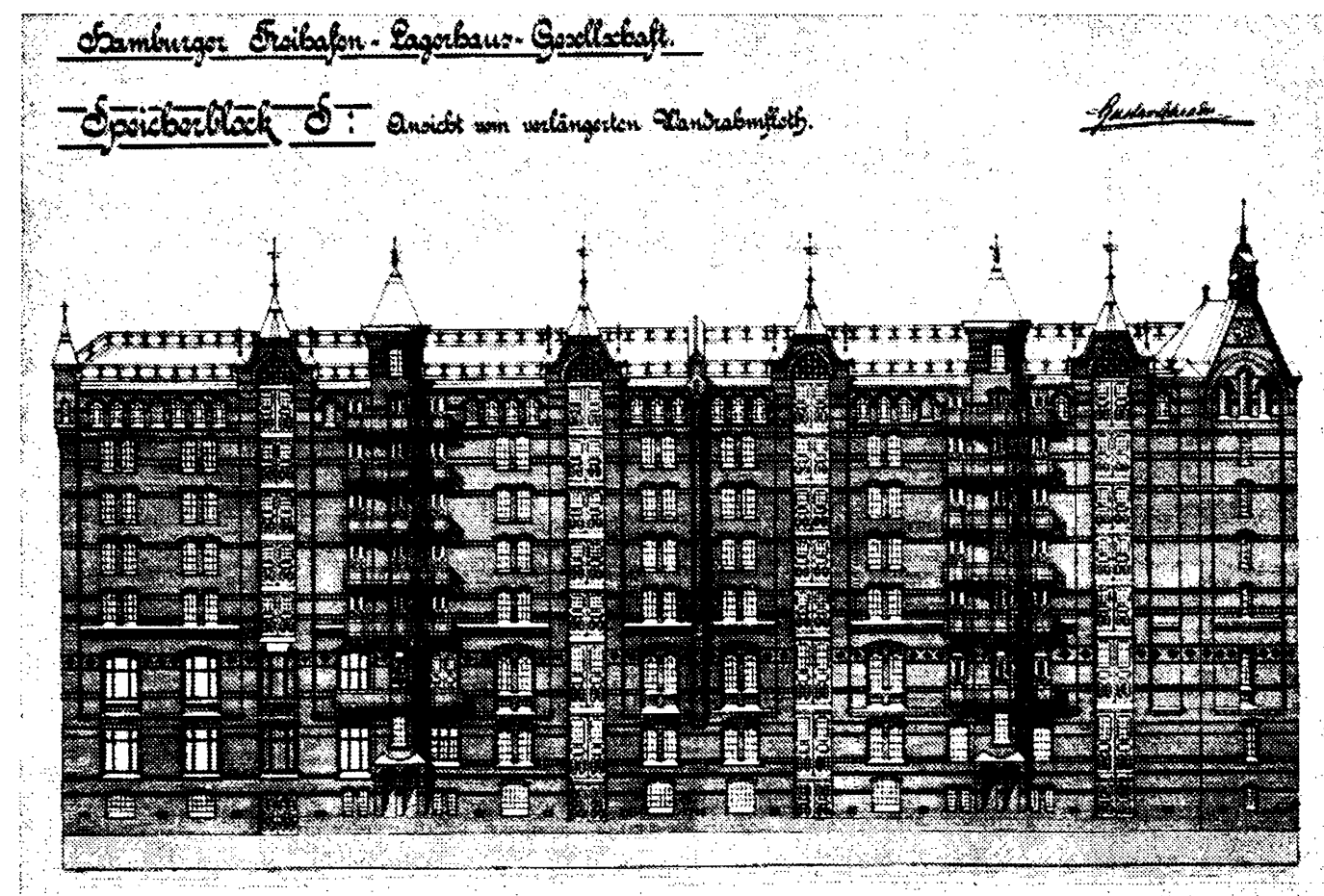

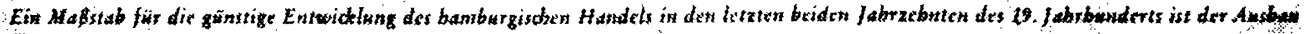

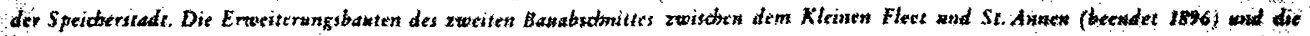

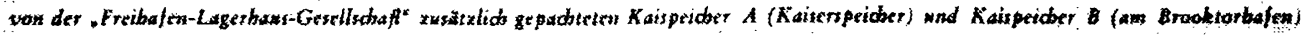

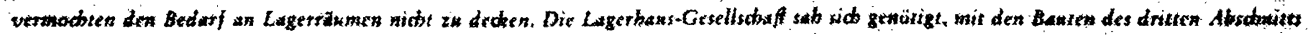

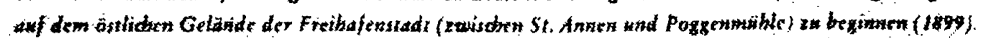

Speicberblock S der Hamburger Freihafen-Lager-Hausgesellschaft (erbaut um I899)

für das billigste Projekt VIIIa, mußte aber einsehen, daß unter Io6 Mill. Mk. nichts zu machen war ${ }^{78}$. Obwohl der Reichszuschuß nicht einmal die Hälfte deckte, wurde der Freihafen 1883 beschlossen. Die tatsächlichen Kosten verliefen sich infolge nachträglicher Änderungen dann auf I I 2,7 Mill. Mk. Damit wurde ein einmaliges Projekt in Deutschland verwirklicht: Eng vereinte Warenlagerung in nächster Nähe der Handelsstadt, große zollfreie Hafenspeicher, nötiger Spielraum für die Lagerung des Massengutes am tiefen Wasser und freie Zollinlandswasserstraße von Böhmen bis zum Meer ${ }^{79}$. Die Hafenindustrie hatte den großen Vorteil, die billigen Rohstoffe aus

${ }^{78}$ Die einzelnen Projekte können an dieser Stelle nicht beschrieben werden. Sie unterschieden sich hauptsächlich in der Größe der Speicherlagerfläche und in den Kostenvoranschlägen. Vergl. Antrag des Senats an die Bürgerschaft v. 3. Januar 1882 nebst Bericht der Senatskommission für die Vorbereitung des Zollanschlusses. Zitiert nach MacElvee, Hamburgs Hafenbaupolitik a. a. O. S. 73. - Baasch, Geschichte Hamburgs Bd. 2 a. a. O. S. $210-$ Wiskemann, Hamburg und die Welthandelspolitik a. a. O., S. 216.

${ }^{79}$ Flügel, Die deutschen Welthäfen a. a. O., S. I I 2, bringt eine gute Zusammenstellung der Hafenausbauten infolge des Zollanschlusses. 
Übersee an Ort und Stelle verarbeiten und wieder ausführen zu können, ohne durch Ein- und Ausfuhrzölle belastet zu werden.

Durch den Zollanschluß wurde der Hafenausbau erst wirklich beschleunigt und der Hafen $z u$ dem, was er heute ist. Insofern ist das Jahr $188 \mathrm{I}$ ebenso wichtig wie die Jahre $1836,1845,1858$ und 1866. Durch den Ausbau eines vom Binnen- zum Oberhafen führenden Fleets zum »Zollkanal« wurde eine deutliche Begrenzung geschaffen. Der Bakenhafen für die größeren Dampfer, der Moldau-, Saale- und Spreehafen für die oberländischen Elbkähne und der Segelschiffhafen sind als unmittelbare Folge des Zollanschlusses zu werten. Schon damals wurde auch die Anlage des Hansa-, Indiaund Petroleumshafens auf der Veddel in Aussicht genommen, das Gebiet um Kuhwärder für künftige Erweiterungen reserviert, das zehn Jahre später I 897 in Hafenbecken verwandelt wurde. Die rasche Erweiterung hing freilich auch damit zusammen, daß sich Hamburg verpflichtet hatte, bis 1888 alle Zollanschlußbauten auszuführen. Die erwarteten » 500 Prozesse« bei der Grundstückserwerbung blieben zwar aus, doch brachte die Aussiedlung von rund 24000 Menschen große soziale Probleme. Unter Führung und Garantie der Norddeutschen Bank wurde die Freihafen-LagerhausGesellschaft errichtet. Hamburg stellte der Gesellschaft 30000 qm pachtweise zur Verfügung, worauf Speicher, Lagerhäuser und Kontore errichtet wurden. Der Staat lieferte baufertigen Grund, Kaimauern, Kräne und Eisenbahnanschluß. Dafür wurde er am Gewinn beteiligt, brauchte aber den Verlust nicht mitzutragen ${ }^{80}$. Auch an die privaten Gesellschaften wurden Speicherplätze verpachtet, freilich nicht in solchem Umfange. Am I5. Oktober 1888 konnte, nachdem beide Teile ihren Vertrag erfüllt hatten, der Zollanschluß feierlich im Beisein des Kaisers vollzogen werden. Die erste Phase im Ausbau des Hamburger Hafens wie der Hamburger Industrialisierung war vollendet. Um 1900 standen alles in allem eine nutzbare Wasserfläche von 185,4 ha und ein Kaigelände von $14,3 \mathrm{~km}$ zu Verfügung. 40 Jahre vorher waren es nur 3,9 ha gewesen. Die Grundlagen für den heutigen modernen Hamburger Hafen waren damit gelegt worden.

so Vergl. die Senats- und Bürgerschaftsverhandlungen r884. Auszugsweise wiedergegeben bei Fligel, Die deutschen Welthäfen a. a. O. - Bubendey-Lorenz, Hamburger Hafen a. a. O. - Meyer-Marwitz, Hamburgs Weg zum Welthafen a. a. O. - MacElwee, Hamburger Hafenbaupolitik a. a. O. - Wiedenfeldt, Die nordwesteuropäischen Welthäfen a. a. O. 